\title{
Metabolic Pathways Involved in Carbon Dioxide Enhanced Heat Tolerance in Bermudagrass
}

\author{
Jingjin Yut ${ }^{1 \dagger}$, Ran $\mathrm{Li}^{1+}$, Ningli Fan', Zhimin Yang ${ }^{1 *}$ and Bingru Huang ${ }^{2 *}$ \\ ${ }^{1}$ College of Agro-grassland Science, Nanjing Agricultural University, Nanjing, China, ${ }^{2}$ Department of Plant Biology and \\ Pathology, Rutgers, The State University of New Jersey, New Brunswick, NJ, United States
}

OPEN ACCESS

Edited by:

Luis A. J. Mur,

Aberystwyth University,

United Kingdom

Reviewed by:

Lucia Guidi,

University of Pisa, Italy

M. B. Kirkham,

Kansas State University, United States

*Correspondence:

Zhimin Yang

nauyzm@njau.edu.cn

Bingru Huang

huang@aesop.rutgers.edu

tThese authors have contributed equally to this work.

Specialty section:

This article was submitted to Crop Science and Horticulture,

a section of the journal

Frontiers in Plant Science

Received: 31 March 2017

Accepted: 15 August 2017 Published: 19 September 2017

Citation:

Yu J, Li R, Fan N, Yang Z and Huang B (2017) Metabolic Pathways Involved in Carbon Dioxide Enhanced

Heat Tolerance in Bermudagrass.

Front. Plant Sci. 8:1506.

doi: 10.3389/fpls.2017.01506
Global climate changes involve elevated temperature and $\mathrm{CO}_{2}$ concentration, imposing significant impact on plant growth of various plant species. Elevated temperature exacerbates heat damages, but elevated $\mathrm{CO}_{2}$ has positive effects on promoting plant growth and heat tolerance. The objective of this study was to identify metabolic pathways affected by elevated $\mathrm{CO}_{2}$ conferring the improvement of heat tolerance in $\mathrm{a}_{4}$ perennial grass species, bermudagrass (Cynodon dactylon Pers.). Plants were planted under either ambient $\mathrm{CO}_{2}$ concentration $\left(400 \mu \mathrm{mol} \cdot \mathrm{mol}^{-1}\right)$ or elevated $\mathrm{CO}_{2}$ concentration $\left(800 \mu \mathrm{mol} \cdot \mathrm{mol}^{-1}\right)$ and subjected to ambient temperature $\left(30 / 25^{\circ} \mathrm{C}\right.$, day/night) or heat stress $\left(45 / 40^{\circ} \mathrm{C}\right.$, day/night). Elevated $\mathrm{CO}_{2}$ concentration suppressed heat-induced damages and improved heat tolerance in bermudagrass. The enhanced heat tolerance under elevated $\mathrm{CO}_{2}$ was attributed to some important metabolic pathways during which proteins and metabolites were up-regulated, including light reaction (ATP synthase subunit and photosystem I reaction center subunit) and carbon fixation [(glyceraldehyde-3-phosphate dehydrogenase, GAPDH), fructose-bisphosphate aldolase, phosphoglycerate kinase, sedoheptulose-1,7-bisphosphatase and sugars) of photosynthesis, glycolysis (GAPDH, glucose, fructose, and galactose) and TCA cycle (pyruvic acid, malic acid and malate dehydrogenase) of respiration, amino acid metabolism (aspartic acid, methionine, threonine, isoleucine, lysine, valine, alanine, and isoleucine) as well as the GABA shunt (GABA, glutamic acid, alanine, proline and 5oxoproline). The up-regulation of those metabolic processes by elevated $\mathrm{CO}_{2}$ could at least partially contribute to the improvement of heat tolerance in perennial grass species.

Keywords: bermudagrass, elevated $\mathrm{CO}_{2}$, heat stress, metabolites, protein

\section{INTRODUCTION}

Global climate changes involve elevated temperature and $\mathrm{CO}_{2}$ concentration, imposing significant impact on plant growth (Kirkham, 2011). During this century, global temperatures are predicted to rise by $2-5^{\circ} \mathrm{C}$; atmospheric $\mathrm{CO}_{2}$ concentration has increased by $100 \mu \mathrm{mol} \mathrm{mol}^{-1}$ since the beginning of the industrialized era and the concentration is predicted to continue rising at a rate of approximately $2 \mu \mathrm{mol} \mathrm{mol}^{-1}$ per year (Intergovernmental Panel on Climate Change [IPCC], 2007). Previous research has shown that elevated $\mathrm{CO}_{2}$ promotes plant growth under optimal growing temperatures in various plant species (Hamerlynck et al., 2000; Prasad et al., 2002; Qaderi et al., 2006). Recent research also found that elevated $\mathrm{CO}_{2}$ has positive effects on promoting heat 
tolerance in terms of vegetative growth in $\mathrm{C}_{3}$ species, such as rice (Oryza sativa) (Sujatha et al., 2008; Figueiredo et al., 2015; Lai et al., 2015), wheat (Triticum aestivum) (Bencze et al., 2005; Alonso et al., 2009), and cool-season perennial grass species (Yu et al., 2012a, 2014) and $\mathrm{C}_{4}$ plant species, such as Bouteloua gracilis (Read and Morgan, 1996), peanut (Arachis hypogaea) (Prasad et al., 2010), grain sorghum (Sorghum bicolor) (Prasad et al., 2006) and maize (Zea mays) (Abebe et al., 2016). The mechanisms regulating elevated $\mathrm{CO}_{2}$ effects on $\mathrm{C}_{3}$ plant species have been reported, which have been associated with enhanced cellular expansion and cell division resulted from increased carbohydrate availability and changes in proteins and gene transcript levels (Pritchard et al., 1999; Kirkham, 2011; Morgan et al., 2011; Huang and $\mathrm{Xu}, 2015)$. However, metabolic factors underlying elevated $\mathrm{CO}_{2}$ improvement of heat tolerance in $\mathrm{C}_{4}$ perennial grass species are not well understood.

Metabolic and proteomic analysis mostly in $\mathrm{C}_{3}$ plant species demonstrated that elevated $\mathrm{CO}_{2}$ causes changes in various metabolic processes or pathways such as photosynthetic carbon fixation, respiratory metabolism, cellular growth, and stress defense (Fukayama et al., 2009; Yu et al., 2012a, 2014; Burgess and Huang, 2014, 2016). The improved heat tolerance by doubling ambient $\mathrm{CO}_{2}$ concentration in $\mathrm{C}_{3}$ grass species, such as tall fescue (Festuca arundinacea), has been attributed to increases in the accumulation of metabolites, such as organic acids (shikimic acid, malonic acid, glyceric acid, threonic acid, galactaric acid, and citric acid), sugars (sucrose and maltose) and amino acids (valine, serine, and 5-oxoproline) involved in photosynthesis, respiration and amino acid metabolism ( $\mathrm{Yu}$ et al., 2012a). In addition, doubling ambient $\mathrm{CO}_{2}$ concentration significantly increased the accumulation of soluble leaf carbohydrates and activity of adenosine-5' -diphosphoglucose pyrophosphorylase under high temperature in kidney bean (Phaseolus vulgaris) (Prasad et al., 2004). Proteomic profiling of tall fescue exposed to elevated $\mathrm{CO}_{2}$ concentration under heat stress found increased abundance of proteins associated with functions of photosynthetic light reaction, electron transport carrier molecule, ATP generation enzyme and antioxidant system (Yu et al., 2014). It has been reported that $\mathrm{C}_{4}$ plant species are generally less responsive to elevated $\mathrm{CO}_{2}$ than $\mathrm{C}_{3}$ species when they are exposed to their respective optimal temperature conditions (Kirkham, 2011; Huang and $\mathrm{Xu}, 2015)$. Mechanisms of elevated $\mathrm{CO}_{2}$-induced stimulation of photosynthesis in $\mathrm{C}_{3}$ plants were mainly associated with changes in electron transport during in light reaction as well as capacity for carbon fixation and assimilation during dark respiration (Yu et al., 2012b, 2014; Huang and Xu, 2015). However, the key changes in metabolites and proteins induced by elevated $\mathrm{CO}_{2}$ in $\mathrm{C}_{4}$ plants under heat stress have not yet to be determined.

The objective of the current study was to identify metabolic pathways affected by elevated $\mathrm{CO}_{2}$ conferring the improvement of heat tolerance in a $\mathrm{C}_{4}$ perennial grass species, bermudagrass (Cynodon dactylon) widely used as forage and turfgrass species. Understanding changes of metabolites and proteins in $\mathrm{C}_{4}$ species in response to elevated $\mathrm{CO}_{2}$ concentration will provide new insights to mechanisms about elevated $\mathrm{CO}_{2}$-mitigated effects on heat stress.

\section{MATERIALS AND METHODS}

\section{Plant Materials and Growth Conditions}

Stolons of bermudagrass (cv. 'Tifway') plants were collected from the research farm at Nanjing Agricultural University in Nanjing, China, and transplanted into pots $(20 \mathrm{~cm}$ in diameter and $20 \mathrm{~cm}$ in depth) filled with a mixture of soil and sand (soil: sand $=1: 1, \mathrm{v} / \mathrm{v}$ ). Plants were grown in a greenhouse with average temperature of $30 / 22^{\circ} \mathrm{C}$ (day/night), natural sunlight and irrigated once a week with half-strength Hoagland's nutrient solution (Hoagland and Arnon, 1950) to establish canopy and roots for 2 months. During this period, plants were trimmed once a week to keep a canopy height of $4-5 \mathrm{~cm}$. After establishment, plants were transferred to growth chambers (Xubang, Jinan, Shandong province, China) with the temperature of $30 / 25^{\circ} \mathrm{C}$ (day/night), $70 \%$ relative humidity, photosynthetically active radiation of $650 \mu \mathrm{mol} \cdot \mathrm{m}^{-2} \cdot \mathrm{s}^{-1}$ and a 12 -h photoperiod.

\section{Experimental Design and Treatments}

The $\mathrm{CO}_{2}$ concentrations set-up and control in growth chambers followed the same designed as described in Yu et al. (2012a,b). Each $\mathrm{CO}_{2}$ treatment was imposed in four growth chambers on September 1, 2015. In order to evaluate the long-term effects of elevated $\mathrm{CO}_{2}$, plants were grown under the two $\mathrm{CO}_{2}$ concentrations for 70 days prior to the exposure to heat stress. Plants grown under either $\mathrm{CO}_{2}$ treatment was then exposed to $\left(45 / 40^{\circ} \mathrm{C}\right.$ ) (heat stress) or $30 / 25^{\circ} \mathrm{C}$ (non-stress control) in two growth chambers on November 9, 2015 until December 8, 2015. Plants were randomly relocated in each chamber twice per week to avoid confounding effects of environmental variation between different chambers. The $\mathrm{CO}_{2}$ concentration inside each growth chamber was controlled by an automated, open-chamber $\mathrm{CO}_{2}$ control system connected to a gas tank containing $100 \% \mathrm{CO}_{2}(\mathrm{Yu}$ et al., 2015).

The experiment was arranged as factorial design with two $\mathrm{CO}_{2}$ concentrations (ambient $\mathrm{CO}_{2}$ concentration at $400 \pm 10 \mu \mathrm{mol} \cdot \mathrm{mol}^{-1}$ and elevated $\mathrm{CO}_{2}$ concentration at $\left.800 \pm 10 \mu \mathrm{mol} \cdot \mathrm{mol}^{-1}\right)$ and two temperature treatments $\left[30 / 25^{\circ} \mathrm{C}\right.$ (day/night, optimal temperature control) and $45 / 40^{\circ} \mathrm{C}$ (day/night, heat stress)]. Each treatment was repeated in four pots of plants (four replicates).

\section{Measurements of Physiological Indexes}

Leaf net photosynthetic rate $\left(P_{n}\right)$ was determined by inserting 4-5 individual leaves (second full-expanded from the top) collected from each pot to a $6 \mathrm{~cm}^{2}$ cuvette with a portable infrared gas analyzer (Li-6400, LI-COR, Inc., Lincoln, NB, United States). Leaves were placed in a leaf chamber with a built-in red and blue light source of the Li-6400 with the light intensity of $800 \mu \mathrm{mol}$ photon $\cdot \mathrm{m}^{-2} \cdot \mathrm{s}^{-1}$.

For leaf chlorophyll content (Chl), $0.2 \mathrm{~g}$ of fresh leaves were detached from plants and then immersed in dimethyl sulfoxide (DMSO) in dark for at least $72 \mathrm{~h}$ for a complete extraction of total chlorophyll. The absorbance of the Chl extract was measured at wavelengths of 663 and $645 \mathrm{~nm}$, respectively, by a spectrophotometer (Ultrospec 2100 pro, 
Biochrom Ltd., Cambridge, England) to calculate Chla and Chlb content. Chl was determined as described by Arnon (1949). For photochemical efficiency $\left(F_{\mathrm{v}} / F_{\mathrm{m}}\right)$, chlorophyll fluorescence (the ratio of variable to maximum fluorescence as $F_{\mathrm{v}} / F_{\mathrm{m}}$ ) was measured by a fluorescence induction monitor (Bioscientific Ltd., Herts, United Kingdom) following $30 \mathrm{~min}$ dark acclimation through leaf tips.

\section{Metabolites Extraction and Quantification}

The extraction procedure was conducted following the method of Roessner et al. (2000) and Rizhsky et al. (2004). Leaf samples collected at 28 days of treatment were collected and immediately frozen in liquid nitrogen, then stored at $-80^{\circ} \mathrm{C}$ for metabolic profiling analysis. For each sample, frozen dry leaves were ground to a fine powder with liquid nitrogen, and then $25 \mathrm{mg}$ of powder was transferred into a $10 \mathrm{~mL}$ microcentrifuge tubes, and extracted in $1.4 \mathrm{~mL}$ of $80 \%(\mathrm{v} / \mathrm{v})$ aqueous methanol at $23^{\circ} \mathrm{C}$ for $2 \mathrm{~h}$. Ribitol solution of $10 \mu \mathrm{L}\left(2 \mathrm{mg} \cdot \mathrm{mL}^{-1}\right.$ water $)$ as an internal standard was added prior to incubation. Then, extraction was performed in a water bath at $70^{\circ} \mathrm{C}$ for $15 \mathrm{~min}$. Tubes were centrifuged for $30 \mathrm{~min}$ at $9660 \mathrm{gn}$ and the supernatant was decanted into new tubes, $1.4 \mathrm{~mL}$ of water and $0.75 \mathrm{~mL}$ of chloroform were added. The mixture was vortexed thoroughly and centrifuged for $15 \mathrm{~min}$ at $5025 \mathrm{gn}$ and then $1 \mathrm{~mL}$ of the polar phase (methanol/water) was pipetted into HPLC vials and dried in a centrifugal concentrator (Centrivap, Labconco Corporation, Kansas City, MO, United States). The dried polar phase was methoximated with $80 \mu \mathrm{L}$ of $20 \mathrm{mg} \cdot \mathrm{mL}^{-1}$ methoxyamine hydrochloride at $30^{\circ} \mathrm{C}$ for $90 \mathrm{~min}$ and then was trimethylsilylated with $80 \mu \mathrm{L} \mathrm{N}$-methyl$\mathrm{N}$-(trimethylsilyl) trifluoroacetamide (MSTFA) (with 1\% TMCS) for $60 \mathrm{~min}$ at $70^{\circ} \mathrm{C}$.

The Gas Chromatography-Mass Spectrometer (GC-MS) analysis was modified from Qiu et al. (2007). The derivatized extracts were analyzed with a GC coupled with a TurboMassAutosystem XL MS (Perkin Elmer Inc., Waltham, MA, United States). A $1 \mu \mathrm{L}$ extracts was injected into a DB-5MS capillary column $(30 \mathrm{~m} \times 0.25 \mathrm{~mm} \times 0.25 \mu \mathrm{m}$, Agilent $\mathrm{J} \& \mathrm{~W}$ Scientific, Folsom, CA, United States). The inlet temperature was held at $260^{\circ} \mathrm{C}$. After a $6.5 \mathrm{~min}$ solvent delay, initial GC oven temperature was maintained at $60^{\circ} \mathrm{C} ; 1 \mathrm{~min}$ after injection, the GC oven temperature was raised to $280^{\circ} \mathrm{C}$ at a rate of $5^{\circ} \mathrm{C} \cdot \mathrm{in}^{-1}$, and finally maintained at $280^{\circ} \mathrm{C}$ for $15 \mathrm{~min}$. The injection temperature was set at $280^{\circ} \mathrm{C}$ and the ion source temperature was adjusted to $200^{\circ} \mathrm{C}$. Helium was used as the carrier gas with a constant flow rate of $1 \mathrm{~mL} \cdot \mathrm{min}^{-1}$. The measurements were performed through electron impact ionization $(70 \mathrm{eV})$ in the full scan mode (m/z 30-550). The detected metabolites were identified with Turbomass 4.1.1 software (PerkinElmer Inc., Waltham, MA, United States). For GC/MS results, compounds were identified based on retention time (RT) and comparison with reference spectra in mass spectral libraries.

\section{Protein Extraction and Quantification}

Leaf samples were collected from each tube at 28 days, immediately frozen in liquid nitrogen, then ground into fine powder and stored at $-80^{\circ} \mathrm{C}$ until analysis. Proteins were extracted using the trichloroacetic acid (TCA)/Acetone method described from $\mathrm{Xu}$ and Huang (2008). Leaf powder samples $(0.5 \mathrm{~g})$ were homogenized on ice in precipitation solution $(10 \%$ TCA and $0.07 \%$ 2-mercaptoethanol in acetone) for $10 \mathrm{~min}$ and then incubated at $-20^{\circ} \mathrm{C}$ for $2 \mathrm{~h}$. The protein pellet was collected and washed with cold acetone containing $0.07 \%$ 2-mercaptoethanol until the supernatant was colorless. The pellet was then vacuum-dried and suspended in resolubilization solution [ $8 \mathrm{M}$ urea, $2 \mathrm{M}$ thiourea, 2\% CHAPS, 1\% dithiothreitol (DTT), and $1 \%$ pharmalyte]. The suspension was centrifuged at $21000 \mathrm{~g}$ for $20 \mathrm{~min}$ and the supernatant was collected for further protein quantification. Protein content was determined using the method of Bradford (1976). A $10 \mu \mathrm{L}$ aliquot of protein extract was mixed with $0.5 \mathrm{~mL}$ of a commercial color reagent (Bio-Rad Laboratories, Hercules, CA, United States) by a bovine serum albumin (BSA) standard. The absorbance was measured spectrophotometrically at $595 \mathrm{~nm}$ between 5 and $30 \mathrm{~min}$ after reaction.

\section{Two-Dimensional PAGE and Protein Analysis}

An IPGPhor apparatus (GE Healthcare, Waukesha, WI, United States) was used for the first isoelectric focusing (IEF) described by $\mathrm{Xu}$ and Huang (2008). The extracts containing $300 \mu \mathrm{g}$ of sample protein were used for IEF in immobilized $\mathrm{pH}$ gradient (IPG) strips ( $\mathrm{pH} 3.0-10.0$, linear gradient, $13 \mathrm{~cm}$ ), formed by rehydrating strips for $12 \mathrm{~h}$ at room temperature in $250 \mu \mathrm{L}$ of rehydration buffer (8 M urea, $2 \mathrm{M}$ thiourea, $2 \%$ CHAPS, $1 \%$ DTT, $1 \%$ v/v IPG buffer, and $0.002 \%$ bromophenol blue). Following IEF, the IPG strips were equilibrated for $15 \mathrm{~min}$ twice at room temperature in equilibration buffer $(50 \mathrm{mM}$ Tris- $\mathrm{HCl} \mathrm{pH} \mathrm{8.8,} 6 \mathrm{M}$ urea, 30\% glycerol, 2\% SDS, and 1\% DTT), then transferred to the same equilibration buffer containing $2.5 \%$ iodoacetamide instead of $1 \%$ DTT. The second dimension electrophoresis was run on a $12.5 \%$ SDS-polyacrylamide gel with a Hoefer SE 600 Ruby electrophoresis apparatus (GE Healthcare, Waukesha, WI, United States). The running conditions were $5 \mathrm{~mA}$ per strip for $30 \mathrm{~min}$ followed by $20 \mathrm{~mA}$ per strip for about 5 h. Gels were stained with Coomassie brilliant blue G-250 and scanned using a Personal Densitometer SI (63-0016-46, GE Healthcare, Waukesha, WI, United States).

Gel images analysis was performed by Progenesis software (Nonlinear Dynamics, Durham, NC, United States). Automatic default spot analysis settings were coupled with manual correction and editing of spot features. The spot volumes were normalized as a percentage of the total volume of all spots on the gel to correct the variability due to staining. Variance analysis of data was used to test the treatment effects on each transgenic line.

Selected protein spots were manually excised from gels and subjected to a trypsin digestion. The peptides were identified by MALDI-TOF-MS as described by Xu and Huang (2008). Data were searched against the National Center for Biotechnology Information (NCBI) database. Proteins containing at least two peptides with a confidence interval value $>95 \%$ were considered to be successfully identified (Ma et al., 2016). 

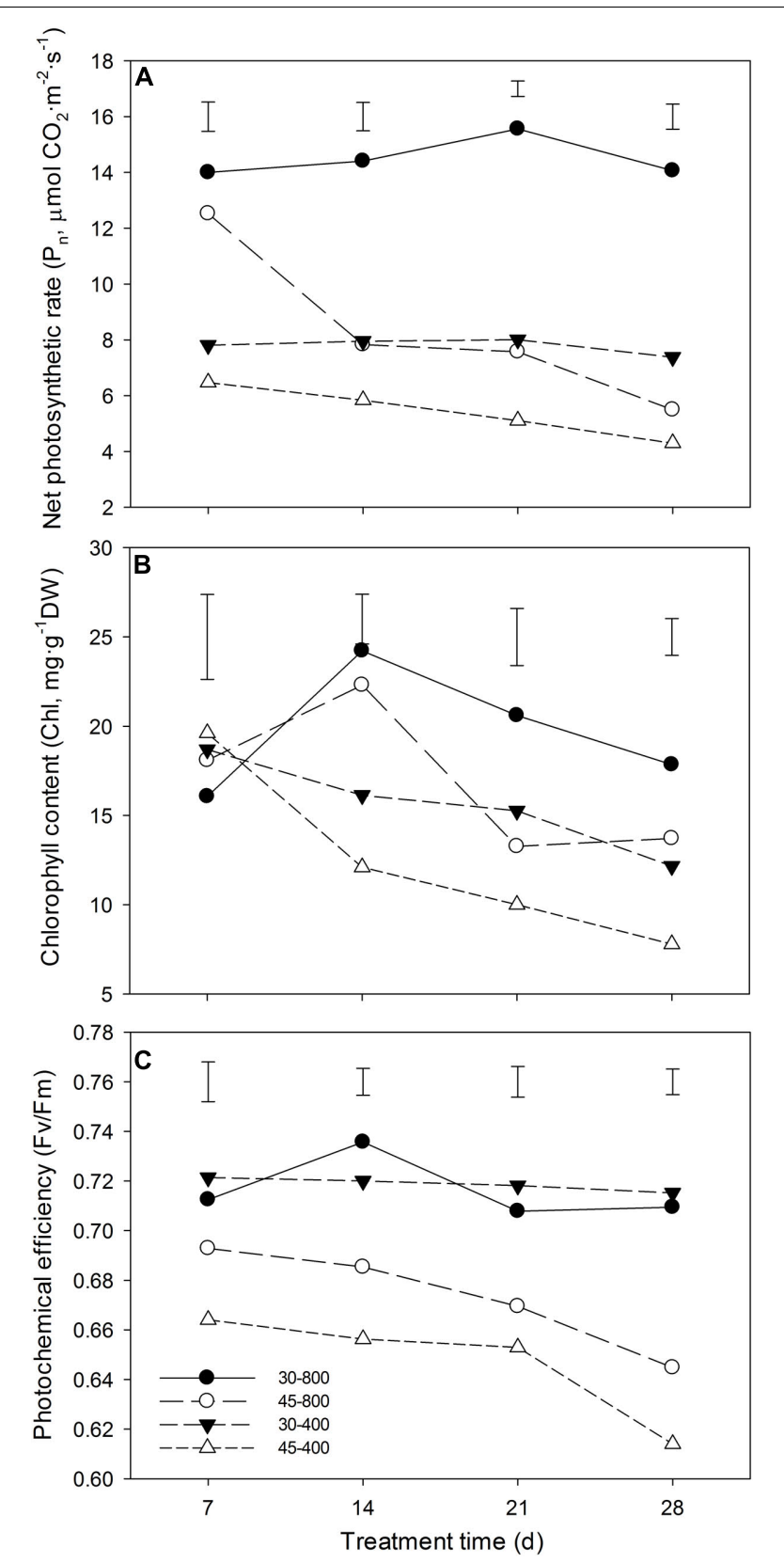

FIGURE 1 | Effects of elevated $\mathrm{CO}_{2}$ concentration $\left(800 \mu \mathrm{mol} \cdot \mathrm{mol}^{-1}\right.$ vs. $\left.400 \mu \mathrm{mol} \cdot \mathrm{mol}^{-1}\right)$ on net photosynthetic rate $\left(P_{\mathrm{n}}\right)(\mathbf{A})$, chlorophyll content (Chl) (B) and (C) photochemical efficiency $\left(F_{\mathrm{v}} / F_{\mathrm{m}}\right)$ in response to heat stress in bermudagrass. The treatments symbols are 30 and 45 for normal temperature control and heat stress and 400 and 800 for ambient $\mathrm{CO}_{2}$ and elevated $\mathrm{CO}_{2}$ concentrations, respectively. Vertical bars indicate significant difference based on $L S D$ values $(P \leq 0.05)$ for the comparison among treatments.

Protein functional classification was performed by Mapman software (Thimm et al., 2004) in combination with the criteria proposed by Bevan et al. (1998). The identified proteins were distributed to different subcellular location by SUBA (Tanz et al., 2013). Gene ontology (GO) for biological process, molecular function and cellular component was conducted by

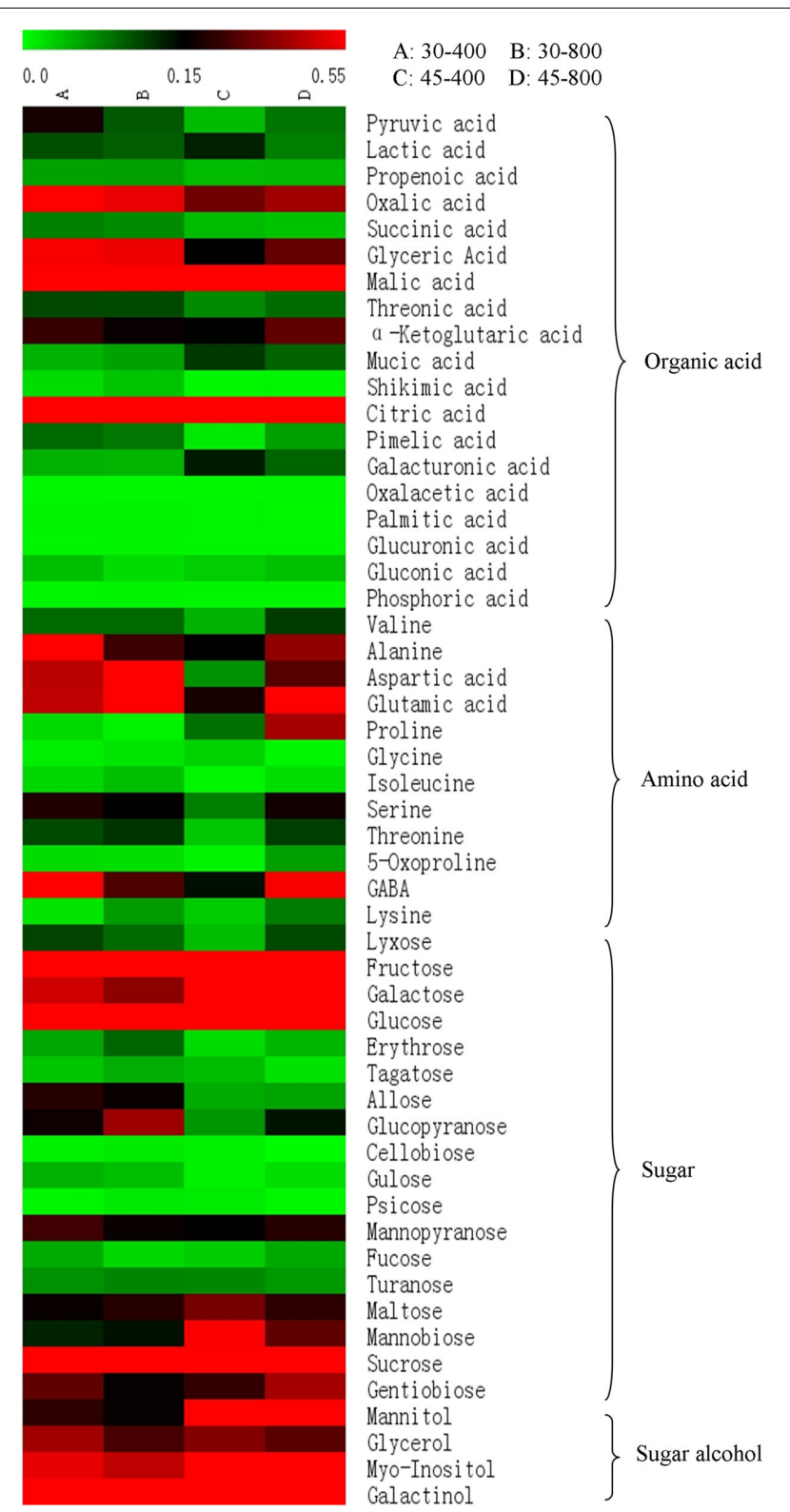

FIGURE 2 | Heat map analysis of total 53 differentially expressed metabolites in response to different temperatures and $\mathrm{CO}_{2}$ concentrations. The treatments symbols are 30 and 45 for normal temperature control and heat stress and 400 and 800 for ambient $\mathrm{CO}_{2}$ and elevated $\mathrm{CO}_{2}$ concentrations, respectively.

the agrigo database ${ }^{1}$; threshold was $-\log 10>4$ (Ma et al., 2016).

\section{Statistical Analysis}

Data were analyzed using statistics software (SPSS 13.0; SPSS Inc., Chicago, IL, United States). Analysis of variance (ANOVA) was used to determine differences among treatment effects at a given treatment time. The means $\pm \mathrm{SE}$ were calculated for each parameter. When a particular F-test was significant, means were

\footnotetext{
${ }^{1}$ http://bioinfo.cau.edu.cn/agriGO/analysis.php
} 
TABLE 1 | Metabolites identified by GC-MS in response to different $\mathrm{CO}_{2}$ concentrations and temperatures in leaves of bermudagrass at 28 days of treatments.

\begin{tabular}{|c|c|c|c|c|c|c|c|}
\hline Compound & $\mathbf{R T}$ & Derivative & $\mathrm{m} / \mathbf{z}$ & Compound & RT & Derivative & $\mathrm{m} / \mathbf{z}$ \\
\hline Pyruvic acid & 8.8 & O-TMS ${ }^{a}, M^{2} O X 1^{b}$ & 174 & Erythrose & 30.306 & O-3TMS,MEOX1 & 205 \\
\hline Lactic acid & 9.091 & O-2TMS & 147 & Tagatose & 31.15 & O-5TMS,MEOX1 & 103 \\
\hline Propenoic acid & 9.819 & O-2TMS & 147 & Pimelic acid & 32.978 & O-3TMS & 300 \\
\hline Alanine & 10.24 & N,O-TMS & 116 & Myo-Inositol & 33.289 & O-6TMS & 305 \\
\hline Oxalic acid & 11.267 & O-2TMS & 147 & Allose & 33.641 & O-5TMS,MEOX1 & 319 \\
\hline Valine & 13.331 & N,O-TMS & 144 & Glucopyranose & 33.802 & O-6TMS & 389 \\
\hline Glycerol & 14.977 & O-2TMS & 205 & Cellobiose & 35.218 & O-8TMS & 204 \\
\hline Isoleucine & 15.47 & O-2TMS & 117 & Gulose & 35.932 & O-5TMS & 204 \\
\hline Proline & 15.547 & N,O-TMS & 142 & Maltose & 40.354 & O-8TMS & 204 \\
\hline Glycine & 15.785 & N,N,O-TMS & 174 & Galacturonic acid & 40.611 & O-5TMS & 204 \\
\hline Succinic acid & 16.059 & O-2TMS & 147 & Mannobiose & 40.972 & O-8TMS & 204 \\
\hline Glyceric Acid & 16.4167 & O-3TMS & 147 & Sucrose & 42.414 & O-8TMS & 361 \\
\hline Serine & 17.274 & N,O,O-TMS & 204 & Galactinol & 47.19 & O-9TMS & 204 \\
\hline Threonine & 17.929 & N,O,O-TMS & 218 & Gentiobiose & 49.095 & O-8TMS & 204 \\
\hline Malic acid & 20.565 & O-3TMS & 147 & Psicose & 26.779 & O-5TMS,MEOX1 & 103 \\
\hline 5-Oxoproline & 21.276 & O-2TMS & 156 & Mannopyranose & 36.968 & O-4TMS & 204 \\
\hline Aspartic acid & 21.328 & O-3TMS & 232 & Fucose & 37.747 & O-4TMS & 204 \\
\hline GABA & 21.528 & N,N,O-TMS & 174 & Glucuronic acid & 31.323 & O-3TMS & 317 \\
\hline Lysine & 21.611 & N,N,O-TMS & 174 & Turanose & 31.491 & O-8TMS & 361 \\
\hline Threonic acid & 22.286 & O-4TMS & 292 & Gluconic acid & 31.59 & O-6TMS & 333 \\
\hline$\alpha$-Ketoglutaric acid & 22.666 & O-2TMS,MEOX1 & 198 & Palmitic acid & 32.566 & O-TMS & 313 \\
\hline Glutamic acid & 23.699 & N,O,O-TMS & 246 & Oxaloacetic acid & 32.701 & O-3TMS & 147 \\
\hline Lyxose & 24.649 & O-4TMS & 103 & Phosphoric acid & 35.269 & O-5TMS & 357 \\
\hline Mucic acid & 27.687 & O-6TMS & 333 & & & & \\
\hline Shikimic acid & 27.912 & O-4TMS & 204 & & & & \\
\hline Citric acid & 28.12 & O-4TMS & 273 & & & & \\
\hline Fructose & 29.109 & O-5TMS,MEOX1 & 307 & & & & \\
\hline Galactose & 29.47 & O-5TMS,MEOX1 & 319 & & & & \\
\hline Glucose & 29.611 & O-5TMS,MEOX1 & 319 & & & & \\
\hline Mannitol & 30.236 & O-6TMS & 319 & & & & \\
\hline
\end{tabular}

$R T$, retention time; $m / z$, mass to charge ratio; aTrimethylsilyl derivative(s), b Methoxime derivative(s).

tested with least significant difference (LSD) at a confidence level of 0.05 .

\section{RESULTS}

\section{Physiological Effects of Elevated $\mathrm{CO}_{2}$}

Under normal temperature, elevated $\mathrm{CO}_{2}$ significantly increased $P_{\mathrm{n}}$ and Chl (Figures 1A,B) while it had no significant effects on $\mathrm{Fv} / \mathrm{Fm}$ (Figure 1C). Under heat stress, plants grown at elevated $\mathrm{CO}_{2}$ had significantly higher $P_{\mathrm{n}}$ (Figure 1A), Chl (Figure 1B), and $F_{\mathrm{v}} / F_{\mathrm{m}}$ (Figure 1C) than that at ambient $\mathrm{CO}_{2}$ concentration.

\section{Effects of Elevated $\mathrm{CO}_{2}$ on Metabolic Profiles}

A total of 53 metabolites, including 18 organic acids and phosphoric acid, 12 amino acids, 18 sugars and 4 sugar alcohols, in responsive to elevated $\mathrm{CO}_{2}$ and heat stress were identified and quantified by GC-MS. The name, RT, derivative and mass to charge $(\mathrm{m} / \mathrm{z})$ as well as the relative expression of each metabolite was presented in Figure 2 and Table 1.
Total content of organic acids, amino acids, sugars, and sugar alcohols were presented in Figure 3. Under normal temperature, no effects of elevated $\mathrm{CO}_{2}$ were detected on total content of organic acids, amino acids, sugars and sugar alcohols compared with ambient $\mathrm{CO}_{2}$. Under heat stress, elevated $\mathrm{CO}_{2}$ resulted in significant increases in the content of organic acids, amino acids, sugars, and sugar alcohols by $52 \%, 2.79$-fold, $29 \%$ and $30 \%$, respectively (Figure 3 ).

For organic acids, under heat stress, plants grown at elevated $\mathrm{CO}_{2}$ exhibited significantly lower content of mucic acid, galacturonic acid, lactic acid, but higher content of pyruvic acid, $\alpha$-ketoglutaric acid, citric acid, glyceric acid, pimelic acid, malic acid and threonic acid compared to those with ambient $\mathrm{CO}_{2}$ (Figures 4A-C). Plants exposed to elevated $\mathrm{CO}_{2}$ had significantly lower content of pyruvic acid and $\alpha$-ketoglutaric acid than those with ambient $\mathrm{CO}_{2}$ under normal temperature (Figure 4B).

For amino acids, under heat stress, the content of all amino acids were increased by elevated $\mathrm{CO}_{2}$ except glycine compared with ambient $\mathrm{CO}_{2}$ (Figure 5). The content of alanine, GABA, and serine (Figure 5C) was 

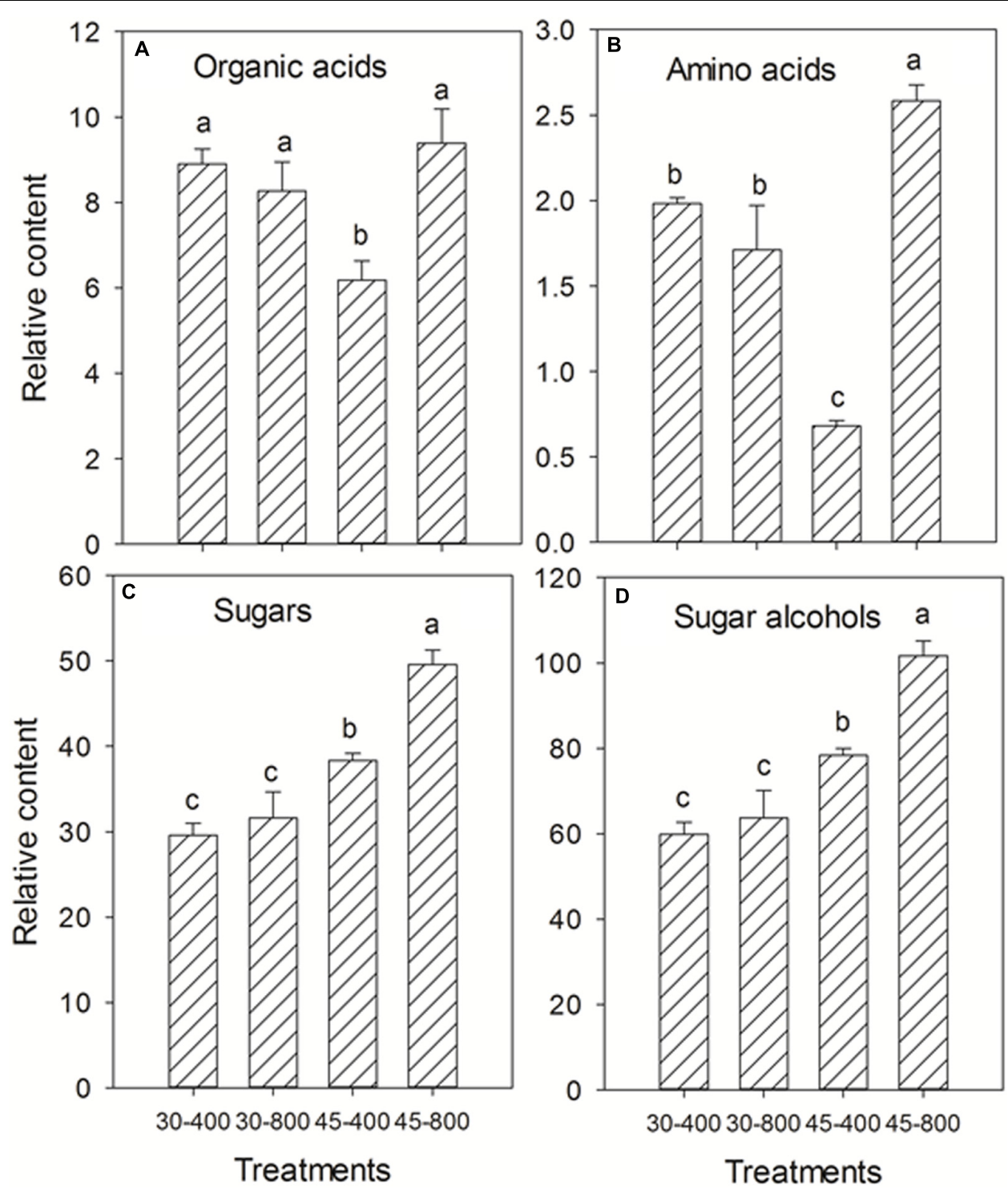

FIGURE 3 | Effects of elevated $\mathrm{CO}_{2}$ concentration on total content of organic acids (A), amino acids (B), sugars (C), and sugar alcohols (D) in response to heat stress in bermudagrass. The treatments symbols are 30 and 45 for normal temperature control and heat stress and 400 and 800 for ambient $\mathrm{CO}_{2}$ and elevated $\mathrm{CO}_{2}$ concentrations, respectively.

significantly lower and the content of aspartic acid, isoleucine, lysine and glutamic acid (Figure 5D) was significantly higher in plants exposed to elevated $\mathrm{CO}_{2}$ compared with ambient $\mathrm{CO}_{2}$ treatments under normal temperature.

For sugars and sugar alcohols, the content of gentiobiose, gulose, lyxose (Figure 6A), and myo-inositol (Figure 7) was decreased while that of erythrose and glucopyranose (Figure 6B) was increased by elevated $\mathrm{CO}_{2}$ compared to plants grown at ambient $\mathrm{CO}_{2}$ concentration under normal temperature. Under heat stress, 8 out of 18 sugars, and two sugar alcohols (mannitol and galactinol) exhibited increases in the content in plants exposed to elevated $\mathrm{CO}_{2}$ compared with ambient $\mathrm{CO}_{2}$ (Figures 6, 7).
Out of 53 identified metabolites, 43 were placed into the metabolic pathways associated with GABA shunt, TCA cycle, sugar and amino acid metabolism (Figure 8). These 43 metabolites included 16 organic acids, 12 amino acids, 11 sugars and 4 sugar alcohols. Under heat stressed conditions, elevated $\mathrm{CO}_{2}$ enhanced the accumulation of metabolites associated with GABA shunt, sugar and amino metabolisms.

\section{Proteomic Responses to Elevated $\mathrm{CO}_{2}$}

A total of 70 and 53 protein spots were differentially expressed in leaves of bermudagrass due to elevated $\mathrm{CO}_{2}$ compared to those at ambient $\mathrm{CO}_{2}$ under normal and high temperature, respectively (Figure 9 and Table 2). 


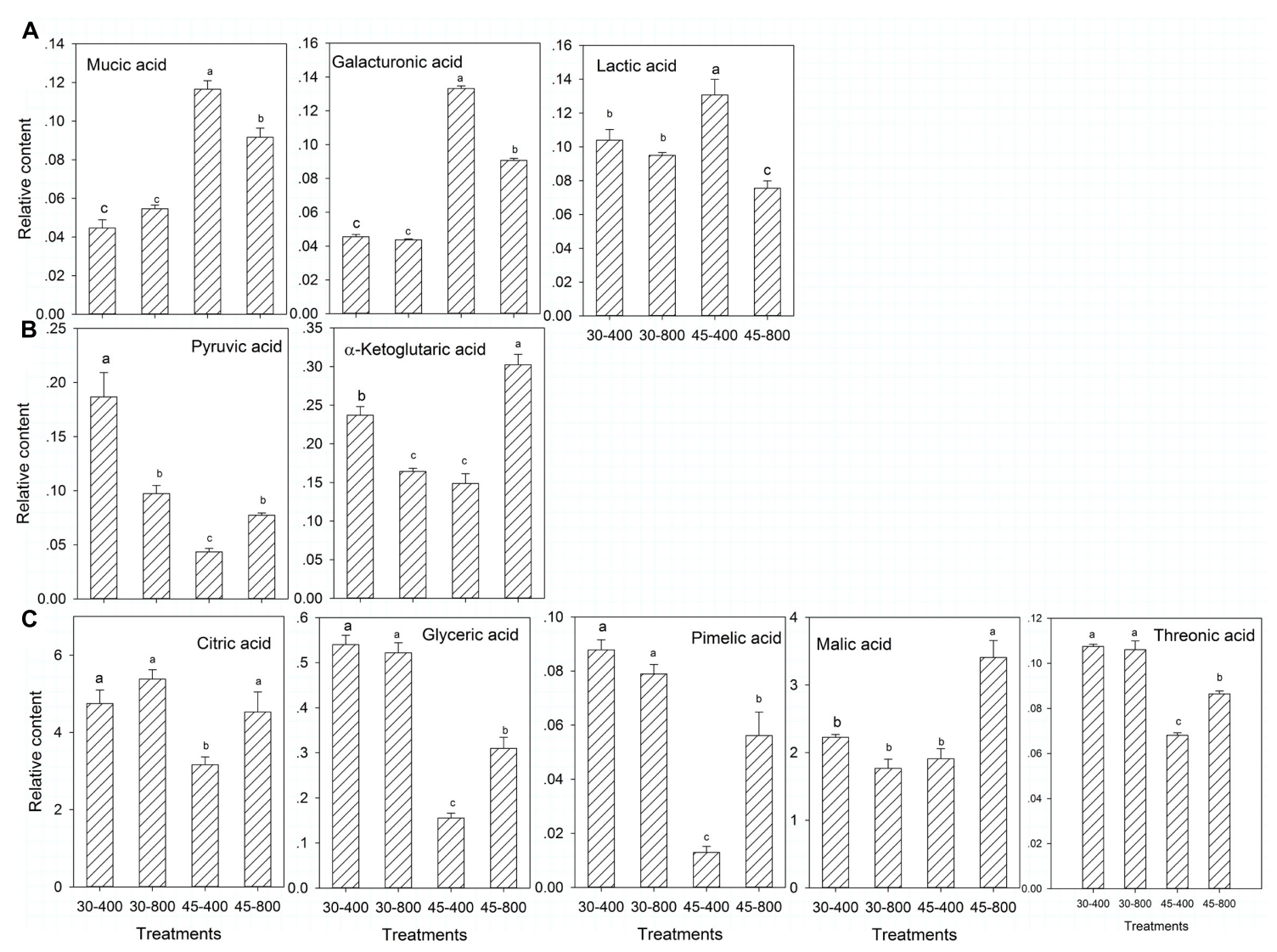

FIGURE 4 | Effects of elevated $\mathrm{CO}_{2}$ concentration on organic acids in response to heat stress in bermudagrass. The treatments symbols are 30 and 45 for normal temperature control and heat stress and 400 and 800 for ambient $\mathrm{CO}_{2}$ and elevated $\mathrm{CO}_{2}$ concentrations, respectively. (A) No changes under $30-800$ and down-regulation under 45-800; (B) No changes under 30-800 and up-regulation under 45-800; (C) Down-regulation under 30-800 and up-regulation under 45-800. Columns marked with different letters presented the significant differences based on LSD values $(P \leq 0.05)$ among treatments.

Those 70 proteins up- or down-regulated by elevated $\mathrm{CO}_{2}$ under normal temperature were found in plastid (67.1\%), cytosol (18.6\%), mitochondrion (5.7\%), peroxisome (4.3\%), cytosol and plasma membrane (1.4\%) and unknown locations (2.9\%) (Figure 10). GO category enrichment showed that 70 proteins participated in various biological processes (metabolic process, response to stress, generation of precursor metabolites and energy, photosynthesis, carbohydrate metabolic process, glycolysis, protein folding, and carbohydrate biosynthetic process), molecular functions (catalytic activity and oxidoreductase activity) and cellular components (intracellular, cell, cytoplasm, organelle, plastid, chloroplast, membrane, protein complex, thylakoid, mitochondrion, envelope, plastoglobule, cytosol, stromule, and photosystem) (Figure 11A).

The majority of these 53 proteins up- or down-regulated by elevated $\mathrm{CO}_{2}$ under heat stress mainly distributed in plastid (62.3\%) followed by cytosol (17\%) (Figure 10). GO category enrichment indicated that the biological processes regulated by $\mathrm{CO}_{2}$ included cellular metabolic process, responses to stress, response to abiotic stimulus, generation of precursor metabolites and energy, photosynthesis, response to inorganic substance, electron transport chain, carbohydrate metabolism, molecular functions (catalytic activity and oxidoreductase activity) and cellular components (cytoplasm, intracellular, cell, organelle, plastid, chloroplast, membrane, mitochondrion, thylakoid, protein complex, envelope, photosystem, and stromule) (Figure 11B).

Based on the Venn analysis, 18 and 19 differential proteins were up-regulated by elevated $\mathrm{CO}_{2}$ only under either normal temperature or heat stress, respectively (Figure 12A). Elevated $\mathrm{CO}_{2}$ caused 12 proteins to be up-regulated regardless of temperature (Figure 12A). A total of 40 proteins were downregulated by elevated $\mathrm{CO}_{2}$ under normal and high temperature (Figure 12B). There were 27 proteins down-regulated under normal temperature and 7 proteins down-regulated under heat stress alone due to elevated $\mathrm{CO}_{2}$ treatment. The differentially expressed proteins in responses to elevated $\mathrm{CO}_{2}$ and heat stress were classified into different functional categories (Figure 13).

Under normal temperature condition, the differential proteins caused by elevated $\mathrm{CO}_{2}$ compared with ambient $\mathrm{CO}_{2}$ were involved in photosynthesis (55.7\%), followed by amino acid metabolism $(8.6 \%)$, glycolysis $(7.1 \%)$, protein synthesis and degradation (4.3\%), stress defense (8.6\%), nucleotide metabolism 


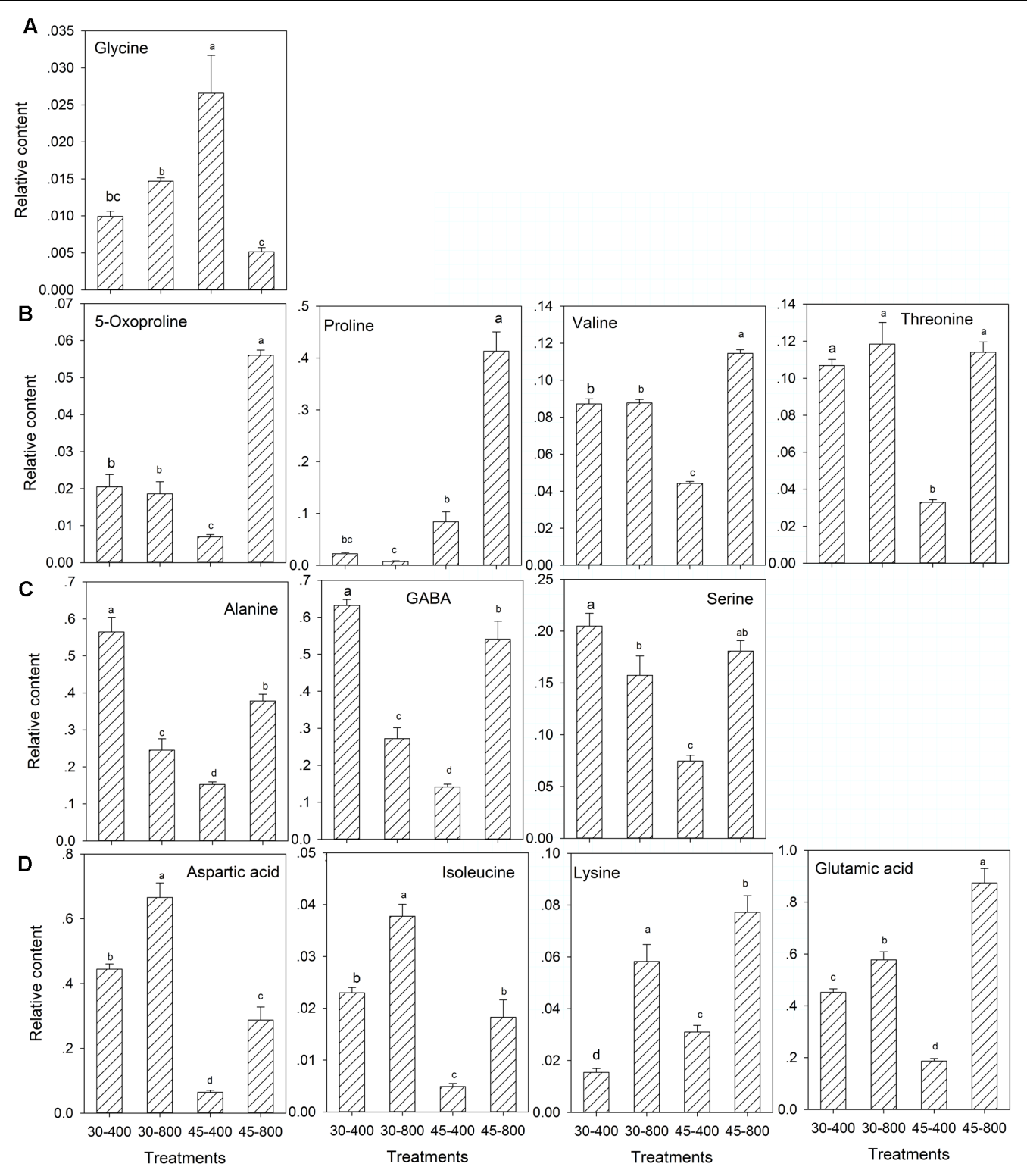

FIGURE 5 | Effects of elevated $\mathrm{CO}_{2}$ concentration on amino acids in response to heat stress in bermudagrass. The treatments symbols are 30 and 45 for normal temperature control and heat stress and 400 and 800 for ambient $\mathrm{CO}_{2}$ and elevated $\mathrm{CO}_{2}$ concentrations, respectively. (A) No changes under $30-800$ and down-regulation under 45-800; (B) No changes under 30-800 and up-regulation under 45-800; (C) Down-regulation under 30-800 and up-regulation under 45-800; (D) Up-regulation under both 30-800 and 45-800. Columns marked with different letters presented the significant differences based on LSD values $(P \leq 0.05)$ among treatments.

(4.3\%), and the remaining (11.4\%) including those unknown functions (Figure 13A). For proteins related to photosynthesis, significant increases in the relative fold change were found in ATP synthase subunit (ATPA, n476) by 1.5 -fold, rubisco large subunit (RBCL, n551, n561, n574) by 1.1- to 2.6-fold, glyceraldehyde-3phosphate dehydrogenase (GAPDH, n660, n762, n770, n795) by 1.1 - to 1.4-fold, ATP synthase subunit gamma (ATPC, n769) by 1.6-fold, fructose-bisphosphate aldolase (FBA, n781) by 1.4-fold, ferredoxin-NADP reductase (FNR, n865) by 1.3-fold, oxygenevolving enhancer protein (OEE, n941) by 1.6-fold, chlorophyll a-b binding protein (LHC, n1066, n1076, n1127, n1195) by 1.3- to 2.4-fold, cytochrome b6-f complex iron-sulfur subunit (PGR, $\mathrm{n} 1364$ ) by 2.0 -fold, rubisco small chain (RBCS, n1650) by 1.5 fold (Figure 14A). Other 21 proteins involved in photosynthesis [(chaperonin-60 alpha, CPN60A), n411 by 1.14-fold; (cpn60 chaperonin family protein, CPN60B), n417 by 1.52 -fold; n486, ATPA by 1.53 -fold; n525, n530 and n537, ATPB by 1.17 - to 1.23-fold; n666, GAPDH by 1.23-fold; (Phosphoglycerate kinase, PGK), n673, n675 and n678 by 1.17- to 1.21-fold; (Sedoheptulose1,7-bisphosphatase, SBPase), n705 by 1.18-fold; n793 and n794, FBA by $1.22-1.35$; n942, OEE by 1.37 -fold; n1073, TIM by 1.36 fold; (Photosystem I reaction center subunit, Psa), PsaD, n1403 

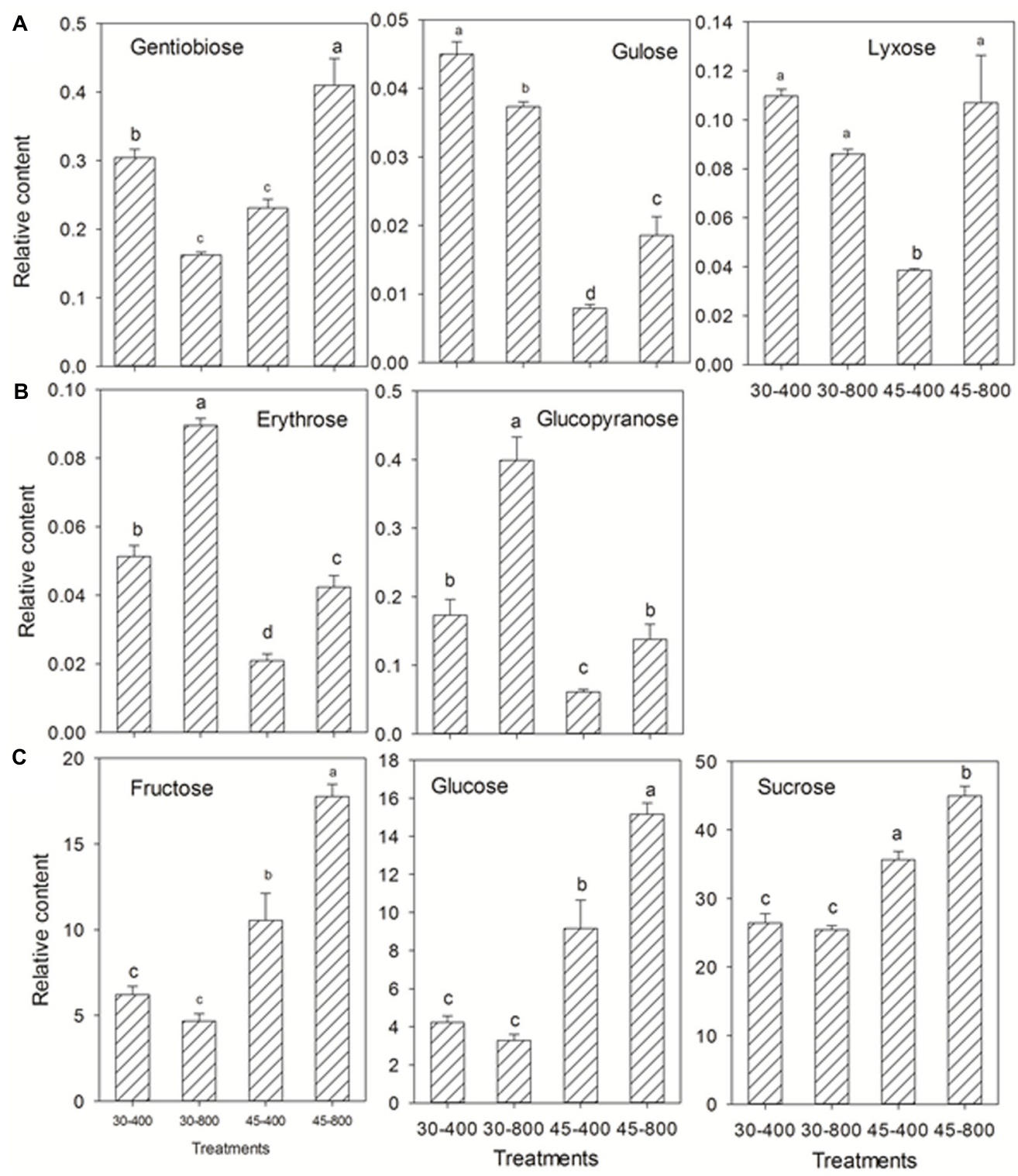

FIGURE 6 | Effects of elevated $\mathrm{CO}_{2}$ concentration on sugars in response to heat stress in bermudagrass. The treatments symbols are 30 and 45 for normal temperature control and heat stress and 400 and 800 for ambient $\mathrm{CO}_{2}$ and elevated $\mathrm{CO}_{2}$ concentrations, respectively. (A) Down-regulation or no changes under 30-800 and down-regulation under 45-800; (B) Up-regulation under both 30-800 and 45-800; (C) No changes under 30-800 and up-regulation under 45-800. Columns marked with different letters presented the significant differences based on LSD values $(P \leq 0.05)$ among treatments.

and $\mathrm{n} 1410$ by 1.47 - to 2.11 -fold; $\mathrm{n} 1473$, PsaE by 1.23 -fold; $\mathrm{n} 1507$, ATPE by 1.3-fold; $n 1511$, PsbQ by 2.02-fold; $n 1802$, PsaH by 1.89 fold] were significantly down-regulated by elevated $\mathrm{CO}_{2}$ under normal temperature compared with ambient $\mathrm{CO}_{2}$ (Figure 14A).

Among proteins associated with the function of protein synthesis and degradation, cytokinin inducible protease (CLPC, $\mathrm{n} 196)$ had a 1.9-fold up-regulation and the other two [(elongation factor, EF), n598 and n616] with 1.2- to 3.0-fold down-regulation compared with ambient $\mathrm{CO}_{2}$ under normal temperature. Transketolase (n324) involved in oxidative pentose phosphate showed a 1.8-fold increase in response to elevated $\mathrm{CO}_{2}$
(Figure 14A). Proteins involved in amino acid metabolism exhibited increases in methionine synthase protein (MS, n248, n250) by 1.4- to 1.7-fold and cysteine synthase C1 (CSase, n814) by 1.6 -fold as well as decreases in aspartate aminotransferase (ASP, n736, n760) by 1.3- to 1.5 -fold and S-adenosylmethionine synthase (SAMS, n619) by 1.3-fold in plants grown at elevated $\mathrm{CO}_{2}$ compared with ambient $\mathrm{CO}_{2}$. GAPDH associated with glycolysis were all down-regulated by 1.4- to 1.9-fold (n382, n776, n784) under elevated $\mathrm{CO}_{2}$ except n808, which was increased by 2.4-fold under elevated $\mathrm{CO}_{2}$ concentration. There were six proteins associating with stress defense of which four proteins 


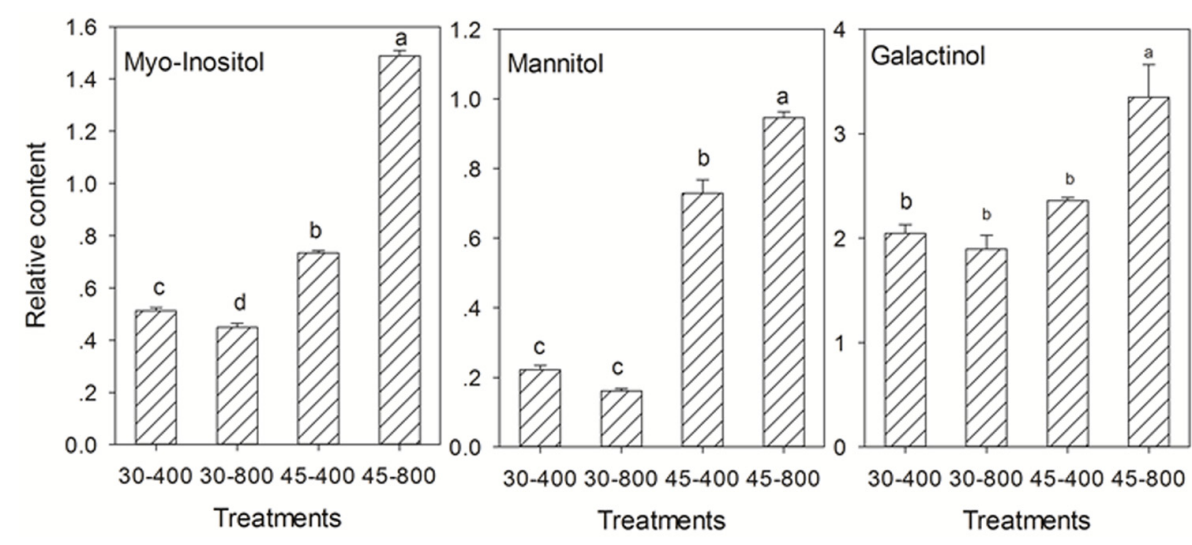

FIGURE 7 | Effects of elevated $\mathrm{CO}_{2}$ concentration on sugar alcohols in response to heat stress in bermudagrass. The treatments symbols are 30 and 45 for normal temperature control and heat stress and 400 and 800 for ambient $\mathrm{CO}_{2}$ and elevated $\mathrm{CO}_{2}$ concentrations, respectively. Columns marked with different letters presented the significant differences based on LSD values $(P \leq 0.05)$ among treatments.

[Heat shock protein (Hsp) 90, n238; Hsp 70, n300; Catalase, n447; Ascorbate peroxidase, n1019] were up-regulated by 1.2 - to 1.4fold and tow proteins (Hsp 70, n303; 2-cys peroxiredoxin BAS1, $\mathrm{n} 1173)$ were down-regulated by 1.1 - to 1.2 -fold under elevated $\mathrm{CO}_{2}$ concentration (Figure 14B).

Under heat stress, elevated $\mathrm{CO}_{2}$-regulated proteins were classified the into following functional categories: photosynthesis (52.8\%), TCA cycle (11.3\%), stress defense (9.4\%), glycolysis (7.5\%), amino acid metabolism (5.7\%), nucleotide metabolism (3.8\%), metal handling (1.9\%), major CHO metabolism (1.9\%), protein synthesis $(1.9 \%)$, cell cycle $(1.9 \%)$ and transport $(1.9 \%)$ (Figure 13B). Proteins associated with photosynthesis were mainly up-regulated by elevated $\mathrm{CO}_{2}$ under heat stress, including CPN60A (h712) by 1.2-fold, CPN60B (h730, h736) by $1.2-$ to 1.3-fold, ATP synthase subunit beta (ATPB, n826) by 1.4-fold, RBCL (h843) by 1.5 -fold, PGK, (h1067) by 1.3 -fold, GAPDH (h1150, h1162, h1162, h1192) by 1.3-fold, SBPase (h1154, h1157) by 1.3-fold, ATPC (h1176) by 1.3-fold, FBA (h1211, h1233) by 1.3 - to 1.5-fold, OEE (h1398) by 2.1-fold, LHC (h1655) by 1.6fold, PGR (h1900, h1930) by 1.2- to 1.7-fold, PsaD (h1905) by 2.5-fold, photosystem I reaction center subunit N (PsaN, h2563) by 1.5 -fold (Figure 15A). One protein associated with protein synthesis was upregulated by elevated $\mathrm{CO}_{2}$ under heat stress (Figure 15A). All proteins involved in amino acid metabolism and nucleotide metabolism were up-regulated by elevated $\mathrm{CO}_{2}$ under heat stress, including MS (1.6-fold), SAMS (1.5-fold), CSase (1.4-fold), pyrophosphorylase 6 (PPa6, 1.7-fold), adenylate kinase (ADK, 1.5-fold). Most TCA cycle related proteins [(Malic enzyme, ME), h716 and h724] by 1.4- to 1.5-fold; [(Malate dehydrogenase, MDH), h1237, h1242 and h1258] by 1.2- to 1.5-fold)] were up-regulated by elevated $\mathrm{CO}_{2}$ compared with ambient $\mathrm{CO}_{2}$ during heat stress (Figure 15B).

\section{DISCUSSION}

Previous studies have shown positive effects of elevated $\mathrm{CO}_{2}$ on plant growth of $\mathrm{C}_{4}$ species under optimal temperature conditions
(Huang and $\mathrm{Xu}, 2015$ ). In this study, elevated $\mathrm{CO}_{2}$ significantly improved physiological activities of $\mathrm{C}_{4}$ bermudagrass under heat stress or mitigated heat stress damages, as manifested by physiological indexes, including higher leaf $P_{\mathrm{n}}, F_{\mathrm{v}} / F_{\mathrm{m}}$ and Chl. The positive physiological effects were associated with changes in various metabolic pathways regulated by elevated $\mathrm{CO}_{2}$. Metabolic and proteomic analysis in this study indicated that the underlying mechanisms of elevated $\mathrm{CO}_{2}$-mitigation of heat stress were mainly related to photosynthesis, respiration (glycolysis and TCA cycle), amino acid metabolism, and GABA shunt, and some of the metabolic factors regulated by elevated $\mathrm{CO}_{2}$ in the $\mathrm{C}_{4}$ grass species, bermudagrass, in this study are in common and some are different from those previously found in $\mathrm{C}_{3}$ grass species ( $\mathrm{Yu}$ et al., 2014; Burgess and Huang, 2016). Due to the large number of metabolites and the complexity of metabolic pathways involved in $\mathrm{CO}_{2}$ effects, the following sections focused on the discussion of unique or different metabolic pathways found in bermudagrass in our study from those findings previously reported in other $\mathrm{C}_{3}$ plant species.

\section{Proteins and Metabolites in Photosynthesis Regulated by Elevated $\mathrm{CO}_{2}$ under Heat Stress}

In our present study, 67 out of 123 proteins (54.5\%) associated with photosynthetic pathways, including proteins involved in electron transport chain and Calvin cycle, were responsive to elevated $\mathrm{CO}_{2}$ concentration under normal and high temperatures, as shown by the decrease or increase in their abundance (Figure 16). Under heat stress, the majority of proteins involved in photosynthesis exhibited accumulation in response to elevated $\mathrm{CO}_{2}$ concentration, such as ATP synthase subunit (h826, h1176), photosystem I reaction center subunit [(PsaD, h1905) and (PsaN, h2563)] in light reactions of photosynthesis, and fructose-bisphosphate aldolase (FBA, h781, h1211, h1233), phosphoglycerate kinase (PGK, h1067) and sedoheptulose-1,7-bisphosphatase (SBPase, h1154, h1157) in Calvin cycle (Figure 15). FBA is a primary enzyme involved 


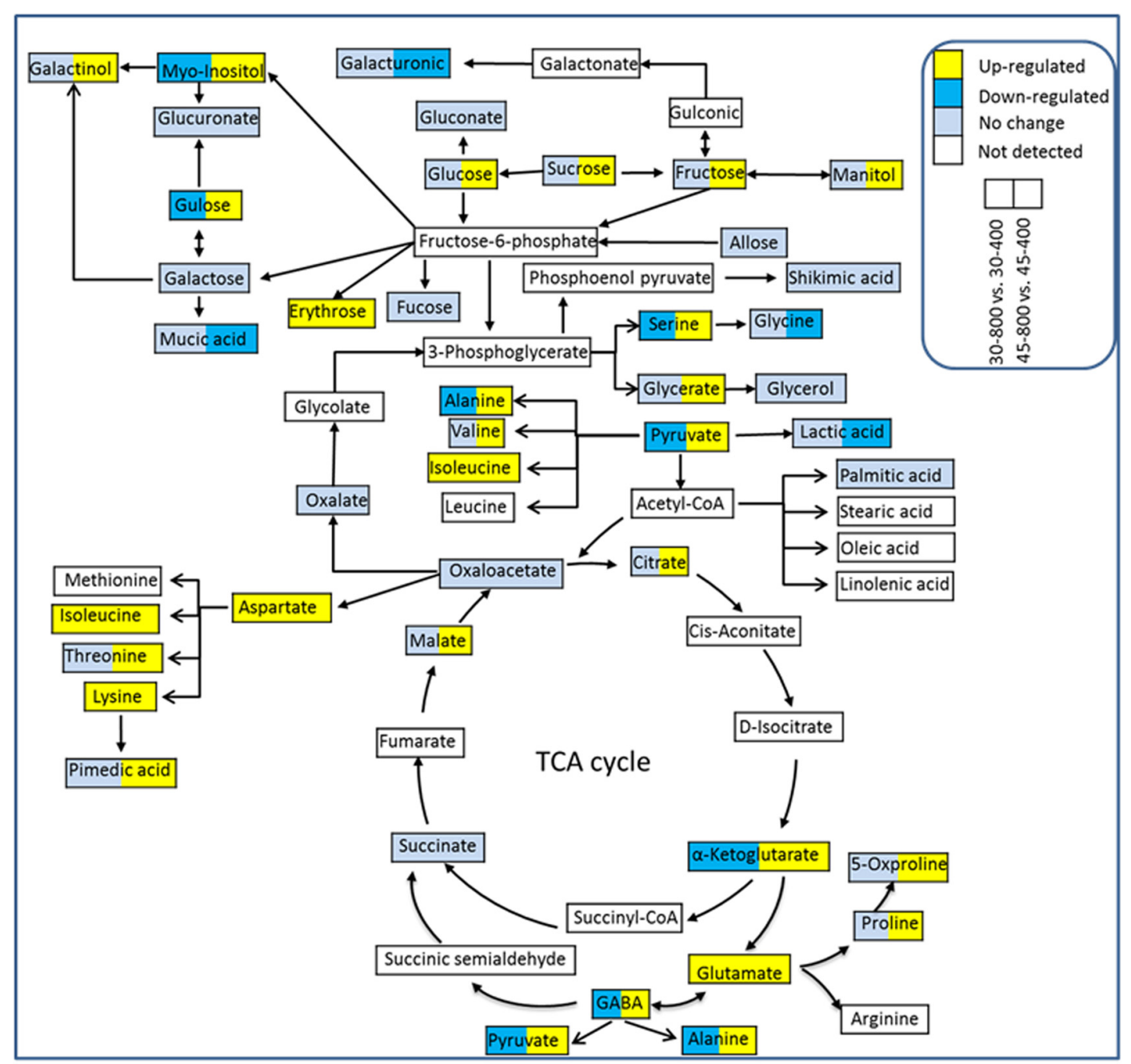

FIGURE 8 | The metabolic pathways associated with differentially expressed metabolites. The treatments symbols are 30 and 45 for normal temperature control and heat stress and 400 and 800 for ambient $\mathrm{CO}_{2}$ and elevated $\mathrm{CO}_{2}$ concentrations, respectively.
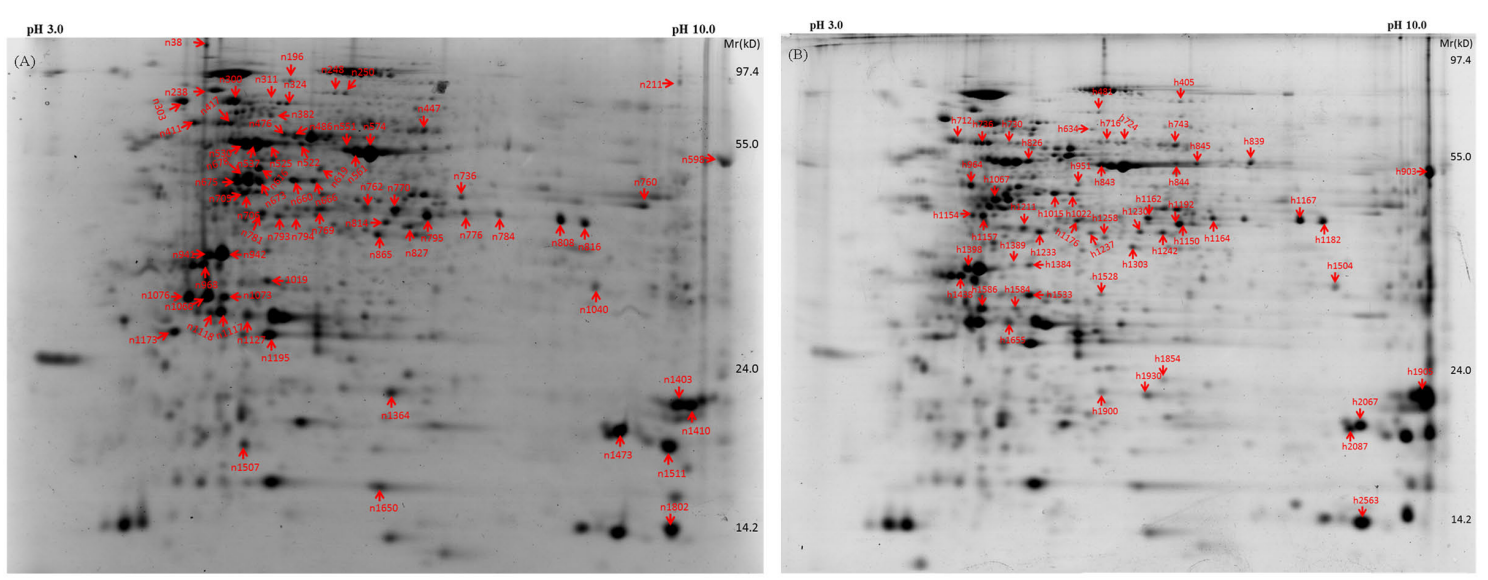

FIGURE 9 | Representative gels of 2-D with differentially expressed proteins identified in bermudagrass grown under normal temperature (A) and heat stress (B) at 28 days of treatments. Labels of spots in each gel were consistent with Table 2. 
TABLE 2 | Differentially expressed proteins in response to different $\mathrm{CO}_{2}$ concentrations and temperatures by comparison between elevated $\mathrm{CO}_{2}$ and ambient $\mathrm{CO}_{2}$ in leaves of bermudagrass at 28 days of treatments.

\begin{tabular}{|c|c|c|c|c|c|}
\hline Spot no. & Unipro. ID & Pro. name [species] & pl & MW & PM \\
\hline n38 & AOA0A9D510 & Uncharacterized protein [Arundo donax] & 11.472786 & 20592.018 & 2 \\
\hline n196 & COPFV4 & Cytokinin inducible protease1 [Zea mays] & 6.23571 & 102041 & 4 \\
\hline n211 & A0A0A9R3Q6 & Uncharacterized protein [Arundo donax] & 9.6397934 & 10972.589 & 2 \\
\hline n238 & C1K9J1 & Heat shock protein 90 [Zea mays] & 5.004387 & 80090 & 5 \\
\hline n248 & Q8W0Q7 & Methionine synthase protein [Sorghum bicolor] & 5.930443 & 83788.72 & 6 \\
\hline n250 & Q8W0Q7 & Methionine synthase protein [Sorghum bicolor] & 5.930443 & 83788.72 & 6 \\
\hline n300 & X4Z319 & Heat shock protein 70 [Saccharum hybrid cultivar] & 5.127754 & 71034.47 & 7 \\
\hline n303 & A4ZYQ0 & Chloroplast heat shock protein 70 [Pennisetum americanum] & 5.233284 & 73010.5 & 5 \\
\hline n311 & K4AEH8 & Glutathione S-transferase [Arabidopsis thaliana] & 5.5051193 & 25757.487 & 2 \\
\hline n324 & Q7SIC9 & Transketolase, chloroplastic [Zea mays] & 5.466347 & 72993.41 & 2 \\
\hline n382 & K3XFX0 & Phosphoglycerate mutase [Arabidopsis thaliana] & 5.7386093 & 63645.472 & 4 \\
\hline n411 & A0A096PMM2 & Chaperonin-60 alpha [Arabidopsis thaliana] & 5.0534134 & 63186.397 & 2 \\
\hline n417 & COPHP3 & Putative TCP-1/cpn60 chaperonin family protein [Zea mays] & 4.750603 & 44074.17 & 4 \\
\hline n447 & AOA059PYZ3 & Catalase [Saccharum hybrid cultivar] & 6.5794296 & 56439.851 & 2 \\
\hline n476 & A0A059Q9W7 & ATP synthase subunit alpha, chloroplastic [Neyraudia reynaudiana] & 5.7230148 & 55674.804 & 7 \\
\hline n486 & A0A024GW45 & ATP synthase subunit alpha, chloroplastic [Lecomtella madagascariensis] & 5.865181 & 55704.87 & 6 \\
\hline n522 & K3Z2G6 & ATP synthase subunit alpha [Setaria italica] & 5.7027206 & 55314.391 & 3 \\
\hline n525 & A0A024GW49 & ATP synthase subunit beta, chloroplastic [Lecomtella madagascariensis] & 5.306984 & 53954.82 & 6 \\
\hline n530 & A0A059Q9X1 & ATP synthase subunit beta, chloroplastic [Neyraudia reynaudiana] & 5.3016434 & 53997.843 & 8 \\
\hline n537 & AOA024BLCO & ATP synthase subunit beta [Pennisetum americanum] & 5.3069839 & 53910.765 & 7 \\
\hline n551 & A0A0G2UKF5 & Ribulose-1,5-bisphosphate carboxylase/oxygenase large subunit [Orinus thoroldii] & 6.2336807 & 51506.568 & 6 \\
\hline n561 & A0A059Q9V4 & Ribulose-1,5-bisphosphate carboxylase/oxygenas [Neyraudia reynaudiana] & 6.0360794 & 52724.927 & 6 \\
\hline n574 & AOAOU5GUY4 & Ribulose-1,5-bisphosphate carboxylase/oxygenase large subunit [Neostapfiella perrieri] & 6.3398514 & 49871.655 & 7 \\
\hline n598 & A0A059Q008 & Elongation factor 1-alpha [Saccharum hybrid cultivar] & 9.1394882 & 49276.993 & 3 \\
\hline n616 & C0P699 & Elongation factor Tu [Zea mays] & 6.1954422 & 50776.346 & 3 \\
\hline n619 & A0A077JG84 & S-adenosylmethionine synthase [Andropogon virginicus] & 5.5640793 & 43045.785 & 4 \\
\hline n660 & K4AA01 & Glyceraldehyde-3-phosphate dehydrogenase [Setaria italica] & 6.1007004 & 46993.46 & 3 \\
\hline n666 & K4AA01 & Glyceraldehyde-3-phosphate dehydrogenase [Setaria italica] & 6.1007004 & 46993.46 & 2 \\
\hline n673 & K3Z5U9 & Phosphoglycerate kinase [Setaria italica] & 6.0720749 & 49686.217 & 4 \\
\hline n675 & K3Z5U9 & Phosphoglycerate kinase [Setaria italica] & 6.072075 & 49686.22 & 3 \\
\hline n678 & K3XH82 & Phosphoglycerate kinase [Setaria italica] & 8.4882584 & 50239.992 & 4 \\
\hline n705 & B6T2L2 & Sedoheptulose-1,7-bisphosphatase [Zea mays] & 6.074532 & 41816.7 & 3 \\
\hline n706 & K3YTN2 & Glutamine synthetase [Setaria italica] & 5.5121689 & 39158.048 & 2 \\
\hline n736 & K3XHJO & Aspartate aminotransferase [Setaria italica] & 8.8027115 & 50210.455 & 4 \\
\hline $\mathrm{n} 760$ & KЗXHJO & Aspartate aminotransferase [Setaria italica] & 8.8027115 & 50210.455 & 4 \\
\hline n762 & A0A096TAE3 & Glyceraldehyde-3-phosphate dehydrogenase [Zea mays] & 7.0012283 & 42856.79 & 2 \\
\hline n769 & P0C1M0 & ATP synthase subunit gamma, chloroplastic [Zea mays] & 8.4372025 & 39789.807 & 5 \\
\hline $\mathrm{n} 770$ & A0A096TAE3 & Glyceraldehyde-3-phosphate dehydrogenase [Zea mays] & 7.0012283 & 42856.79 & 2 \\
\hline n776 & K3YS38 & Glyceraldehyde-3-phosphate dehydrogenase [Setaria italica] & 9.3867569 & 51746.214 & 2 \\
\hline $\mathrm{n} 781$ & K3ZIS7 & Fructose-bisphosphate aldolase [Setaria italica] & 6.2657242 & 42104.979 & 5 \\
\hline $\mathrm{n} 784$ & $\mathrm{C}_{4} \mathrm{JBS} 8$ & Glyceraldehyde-3-phosphate dehydrogenase [Zea mays] & 6.459267 & 36494.67 & 3 \\
\hline n793 & COPD30 & Fructose-bisphosphate aldolase [Zea mays] & 6.3739243 & 38146.552 & 4 \\
\hline n794 & K3ZIS7 & Fructose-bisphosphate aldolase [Setaria italica] & 6.2657242 & 42104.979 & 5 \\
\hline n795 & A0A096TAE3 & Glyceraldehyde-3-phosphate dehydrogenase [Zea mays] & 7.0012283 & 42856.79 & 2 \\
\hline n808 & K3YIG5 & Glyceraldehyde-3-phosphate dehydrogenase [Setaria italica] & 6.9726028 & 36597.831 & 3 \\
\hline n814 & A0A140GYJ8 & Cysteine synthase C1 [Arabidopsis thaliana] & 7.7287216 & 40549.937 & 2 \\
\hline n816 & K3YIG5 & Glyceraldehyde-3-phosphate dehydrogenase [Setaria italica] & 6.9726028 & 36597.831 & 3 \\
\hline n827 & K3Z7Q4 & Malate dehydrogenase [Setaria italica] & 8.229454 & 35523.89 & 3 \\
\hline n865 & B6TEW2 & Ferredoxin-NADP reductase, leaf isozyme [Zea mays] & 8.372902 & 37506.14 & 2 \\
\hline n941 & B4F9R9 & Oxygen-evolving enhancer protein 1 [Zea mays] & 5.539513 & 35079.65 & 5 \\
\hline n942 & B4F9R9 & Oxygen-evolving enhancer protein 1 [Zea mays] & 5.539513 & 35079.65 & 5 \\
\hline
\end{tabular}


TABLE 2 | Continued

\begin{tabular}{|c|c|c|c|c|c|}
\hline Spot no. & Unipro. ID & Pro. name [species] & pl & MW & PM \\
\hline n968 & B6SQQ0 & Inorganic pyrophosphatase [Zea mays] & 5.788383 & 31736.97 & 2 \\
\hline n1019 & J9QDZ6 & Ascorbate peroxidase [Saccharum hybrid cultivar] & 5.176033 & 27159.67 & 3 \\
\hline n1040 & B4FT85 & Isochorismate synthase 1 [Zea mays] & 7.855827 & 29470.34 & 2 \\
\hline n1066 & B4FNR1 & Chlorophyll a-b binding protein 2 [Zea mays] & 5.140251 & 27815.74 & 3 \\
\hline n1073 & B6UG30 & Triosephosphate isomerase [Zea mays] & 6.139687 & 32392.87 & 2 \\
\hline n1076 & B4FNR1 & Chlorophyll a-b binding protein 2 [Zea mays] & 5.140251 & 27815.74 & 2 \\
\hline n1117 & B6SS26 & Adenylate kinase [Zea mays] & 6.790276 & 31139.68 & 2 \\
\hline $\mathrm{n} 1118$ & K3YIW7 & Adenosine monophosphate kinase [Arabidopsis thaliana] & 7.6875992 & 31556.069 & 2 \\
\hline $\mathrm{n} 1127$ & $\mathrm{~B} 6 S U C_{4}$ & Chlorophyll a-b binding protein 8 [Zea mays] & 8.940819 & 28984.34 & 2 \\
\hline n1173 & $\mathrm{C}_{4} \mathrm{~J} 9 \mathrm{M} 7$ & 2-cys peroxiredoxin BAS1 [Zea mays] & 5.807823 & 28272.36 & 3 \\
\hline n1195 & B6SSN3 & Chlorophyll a-b binding protein 6A [Zea mays] & 6.214775 & 26309.18 & 3 \\
\hline n1364 & B4F9N4 & Cytochrome b6-f complex iron-sulfur subunit [Zea mays] & 8.5790482 & 24054.508 & 3 \\
\hline n1403 & A0A0A6Z9F5 & Photosystem I reaction center subunit II [Saccharum hybrid cultivar] & 9.913979 & 21844.1 & 4 \\
\hline $\mathrm{n} 1410$ & A0A0A6Z9F5 & Photosystem I reaction center subunit II [Saccharum hybrid cultivar] & 9.913979 & 21844.1 & 5 \\
\hline n1473 & B6SPC1 & Photosystem I reaction center subunit IV A [Zea mays] & 9.786659 & 14893.9 & 4 \\
\hline n1507 & A0A024GWT9 & ATP synthase epsilon chain, chloroplastic [Lecomtella madagascariensis] & 5.027992 & 15245.6 & 2 \\
\hline n1511 & B4G259 & Photosystem II Subunit Q [Arabidopsis thaliana] & 9.771919 & 23132.72 & 4 \\
\hline n1650 & A0A0A9IAK2 & Ribulose bisphosphate carboxylase small chain [Arundo donax] & 6.306633 & 14832.18 & 2 \\
\hline n1802 & O65101 & Photosystem I reaction center subunit VI, chloroplastic [Zea mays] & 10.09834 & 14929.3 & 2 \\
\hline h405 & B5AMJ8 & Alpha-1,4 glucan phosphorylase [Zea mays] & 6.8560715 & 94452.824 & 2 \\
\hline h481 & Q8W0Q7 & Methionine synthase protein [Sorghum bicolor] & 5.9304428 & 83788.725 & 6 \\
\hline h634 & A0A096QX48 & Succinate dehydrogenase [ubiquinone] flavoprotein subunit [Zea mays] & 6.0423813 & 63934.221 & 2 \\
\hline h712 & A0A096PMM2 & CPN60A [Arabidopsis thaliana] & 5.0534134 & 63186.397 & 2 \\
\hline h716 & A0A096RAX3 & Malic enzyme [Zea mays] & 8.0004501 & 67809.036 & 2 \\
\hline h724 & A0A096RAX3 & Malic enzyme [Zea mays] & 8.0004501 & 67809.036 & 4 \\
\hline h730 & COPHP3 & Putative TCP-1/cpn60 chaperonin family protein [Zea mays] & 4.7506027 & 44074.173 & 4 \\
\hline h736 & COPHP3 & Putative TCP-1/cpn60 chaperonin family protein [Zea mays] & 5.4693375 & 64030.34 & 5 \\
\hline h743 & A0A059PYZ3 & Catalase [Saccharum hybrid cultivar R570] & 6.5794296 & 56439.851 & 2 \\
\hline h826 & A0A024GW49 & ATP synthase subunit beta, chloroplastic [Lecomtella madagascariensis] & 5.3069839 & 53954.82 & 6 \\
\hline h839 & C5Z2J6 & Catalase [Sorghum bicolor] & 6.6157455 & 56841.332 & 3 \\
\hline h843 & AOA0G2UKF5 & Ribulose-1,5-bisphosphate carboxylase/oxygenase large subunit [Orinus thoroldii] & 6.2336807 & 51506.568 & 6 \\
\hline h844 & C5Z2J6 & Catalase [Sorghum bicolor] & 6.6157455 & 56841.332 & 3 \\
\hline h845 & AOA059Q0R4 & NADP-dependent glyceraldehyde-3-phosphate dehydrogenase [Saccharum hybrid cultivar R570] & 6.8003159 & 53254.56 & 2 \\
\hline h903 & A0A059Q008 & Elongation factor 1-alpha [Saccharum hybrid cultivar R570] & 9.1394882 & 49276.993 & 3 \\
\hline h951 & A0A077JG84 & S-adenosylmethionine synthase [Andropogon virginicus] & 5.5640793 & 43045.785 & 4 \\
\hline h964 & K3ZIKO & Rubisco activase [Arabidopsis thaliana] & 6.1982193 & 47531.255 & 4 \\
\hline h1015 & K4AA01 & Glyceraldehyde-3-phosphate dehydrogenase [Setaria italica] & 6.1007004 & 46993.46 & 3 \\
\hline h1022 & K4AA01 & Glyceraldehyde-3-phosphate dehydrogenase [Setaria italica] & 6.1007004 & 46993.46 & 2 \\
\hline h1067 & K3XH82 & Phosphoglycerate kinase [Setaria italica] & 8.4882584 & 50239.99 & 2 \\
\hline h1150 & A0A096TAE3 & Glyceraldehyde-3-phosphate dehydrogenase [Zea mays] & 7.0012283 & 42856.79 & 2 \\
\hline h1154 & B6T2L2 & Sedoheptulose-1,7-bisphosphatase [Zea mays] & 6.0745316 & 41816.7 & 4 \\
\hline h1157 & B6T2L2 & Sedoheptulose-1,7-bisphosphatase [Zea mays] & 6.0745316 & 41816.7 & 3 \\
\hline h1162 & A0A096TAE3 & Glyceraldehyde-3-phosphate dehydrogenase [Zea mays] & 7.0012283 & 42856.79 & 2 \\
\hline h1164 & K3YS38 & Glyceraldehyde-3-phosphate dehydrogenase [Setaria italica] & 9.3867569 & 51746.214 & 2 \\
\hline h1167 & K3YIG5 & Glyceraldehyde-3-phosphate dehydrogenase [Setaria italica] & 6.9726028 & 36597.831 & 3 \\
\hline h1176 & $\mathrm{P} 0 \mathrm{C} 1 \mathrm{MO}$ & ATP synthase subunit gamma, chloroplastic [Zea mays] & 8.4372025 & 39789.807 & 5 \\
\hline h1182 & K3YIG5 & Glyceraldehyde-3-phosphate dehydrogenase [Setaria italica] & 6.9726028 & 36597.831 & 3 \\
\hline h1192 & AOA096TAE3 & Glyceraldehyde-3-phosphate dehydrogenase [Zea mays] & 7.0012283 & 42856.79 & 2 \\
\hline h1211 & K3ZIS7 & Fructose-bisphosphate aldolase [Setaria italica] & 6.2657242 & 42104.979 & 2 \\
\hline h1230 & A0A140GYJ8 & Cysteine synthase C1 [Arabidopsis thaliana] & 7.7287216 & 40549.937 & 2 \\
\hline h1233 & COPD30 & Fructose-bisphosphate aldolase [Zea mays] & 6.3739243 & 38146.552 & 4 \\
\hline h1237 & K3Z7Q4 & Malate dehydrogenase [Setaria italica] & 8.229454 & 35523.89 & 3 \\
\hline h1242 & K3Z7Q4 & Malate dehydrogenase [Setaria italica] & 8.229454 & 35523.89 & 3 \\
\hline
\end{tabular}


TABLE 2 | Continued

\begin{tabular}{|c|c|c|c|c|c|}
\hline Spot no. & Unipro. ID & Pro. name [species] & pl & MW & PM \\
\hline h1258 & K3XJN7 & Malate dehydrogenase [Setaria italica] & 7.6717911 & 35479.854 & 3 \\
\hline h1303 & B6TEW2 & Ferredoxin-NADP reductase, leaf isozyme [Zea mays] & 8.3729019 & 37506.14 & 2 \\
\hline h1384 & COPK05 & Lactoylglutathione lyase [Zea mays] & 5.8257675 & 32344.8 & 3 \\
\hline h1389 & COPK05 & Lactoylglutathione lyase [Zea mays] & 5.8257675 & 32344.804 & 3 \\
\hline h1398 & B4F9R9 & Oxygen-evolving enhancer protein 1 [Zea mays] & 5.5395126 & 35079.65 & 5 \\
\hline h1438 & K3YUP7 & Pyrophosphorylase 6 [Arabidopsis thaliana] & 5.7826157 & 31748.944 & 2 \\
\hline h1504 & B4FT85 & Isochorismate synthase 1 [Zea mays] & 7.8558273 & 29470.34 & 2 \\
\hline h1528 & K3Y8C6 & Ascorbate peroxidase 4 [Arabidopsis thaliana] & 8.1654739 & 38125.019 & 3 \\
\hline h1533 & B6TVL8 & APx2-Cytosolic Ascorbate Peroxidase [Zea mays] & 5.2829514 & 27201.75 & 3 \\
\hline h1584 & B4FQW0 & Stem-specific protein TSJT1 [Zea mays] & 5.233284 & 24666.251 & 2 \\
\hline h1586 & B6SS26 & Adenylate kinase [Zea mays] & 6.7902756 & 31139.68 & 4 \\
\hline h1655 & $\mathrm{B} 6 S U C_{4}$ & Chlorophyll a-b binding protein 8 [Zea mays] & 8.9408188 & 28984.34 & 3 \\
\hline h1854 & A0A0B4J349 & Peptidyl-prolyl cis-trans isomerase[Zea mays] & 9.4011765 & 26443.981 & 3 \\
\hline h1900 & B4F9N4 & Cytochrome b6-f complex iron-sulfur subunit [Zea mays] & 8.5790482 & 24054.508 & 3 \\
\hline h1905 & A0A0A6Z9F5 & Photosystem I reaction center subunit II [Saccharum hybrid cultivar] & 9.9139786 & 21844.1 & 4 \\
\hline h1930 & B4F9N4 & Cytochrome b6-f complex iron-sulfur subunit [Zea mays] & 8.5790482 & 24054.508 & 3 \\
\hline h2067 & B6SPC1 & Photosystem I reaction center subunit IV A [Zea mays] & 9.7866592 & 14893.9 & 3 \\
\hline h2087 & B6ST36 & Chloroplast oxygen-evolving complex/thylakoid lumenal 25.6kDa protein [Zea mays] & 9.3444595 & 26165.12 & 2 \\
\hline h2563 & B4FAC2 & Photosystem I reaction center subunit N [Zea mays] & 9.2116928 & 15485.72 & 3 \\
\hline
\end{tabular}

$n$, normal temperature $\left(30^{\circ} \mathrm{C}\right) ; \mathrm{h}$, heat stress $\left(45^{\circ} \mathrm{C}\right) ; \mathrm{pl}$, isoelectric point; $\mathrm{MW}(\mathrm{kDa})$, molecular weight; PW, the number of unique peptides matched.

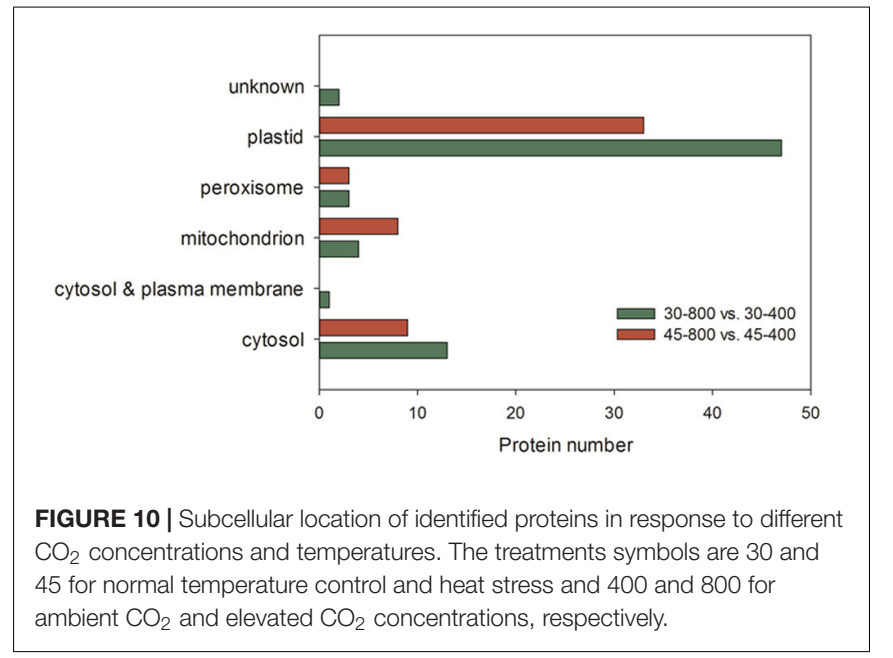

in the sixth reaction of Calvin cycle to convert fructose 1,6-bisphosphate into glyceraldehyde-3-phosphate (G3P) and dihydroxyacetone phosphate as well as ATP (Abbasi and Komatsu, 2004). FBA content at the level of protein significantly increased under elevated $\mathrm{CO}_{2}$ in $\mathrm{C} 3$ tall fescue under heat stress ( $\mathrm{Yu}$ et al., 2014) and creeping bentgrass (Agrostis stolonifera) under both well-water and drought stress (Burgess and Huang, 2016). SBPase functions as a bisphosphatase enzyme catalyzing sedoheptulose 1,7-bisphosphate dephosphorylation to sedoheptulose-7-phosphate during the regeneration phase of Calvin cycle (Raines et al., 1999). Overexpression of SBPase in $\mathrm{C}_{3}$ tobacco (Nicotiana tabacum) had higher photosynthesis at elevated $\mathrm{CO}_{2}$ compared with that at ambient $\mathrm{CO}_{2}$ under field conditions (Rosenthal et al., 2011). The benefits of SBPase on the stimulation of photosynthesis depended on light intensity (Lefebvre et al., 2005; Rosenthal et al., 2011). Therefore, our study and another case in creeping bentgrass, conducted in light saturated growth chambers, the abundance of SBPase was enhanced by elevated $\mathrm{CO}_{2}$ under abiotic stresses (Burgess and Huang, 2016). FBA is a primary enzyme involved in the sixth reaction of Calvin cycle to convert fructose 1,6-bisphosphate into glyceraldehyde-3-phosphate (G3P), dihydroxyacetone phosphate and ATP (Abbasi and Komatsu, 2004). In addition, FBA could directly affect ribulose-1,5-bisphosphate (RuBP) regeneration which actions as substrate of carbon fixation (Taiz and Zeiger, 2010). FBA content at the level of protein showed the grater accumulation in elevated $\mathrm{CO}_{2}$ in $\mathrm{C}_{3}$ tall fescue under heat stress (Yu et al., 2014) and creeping bentgrass (Agrostis stolonifera) under both well-water and drought stress (Burgess and Huang, 2016). PGK is a major enzyme catalyzing the phosphorylation of 3-phosphoglycerate to produce 1, 3-bisphosphoglycerate and $\mathrm{ADP}$ which is one of vital steps regenerating RuBP during Calvin cycle (Bernstein et al., 1997). The regulation of FBA and PGK induced by elevated $\mathrm{CO}_{2}$ indicated that elevated $\mathrm{CO}_{2}$ availability in atmosphere could be helpful for sustaining ATP supply and RuBP regeneration for plant growth under heat stress. ATP synthase is a critical enzyme for creating energy storage molecule ATP. Under high $\mathrm{CO}_{2}$ availability, ATP synthase was found to decline in wheat grain (Högy et al., 2009). To our knowledge, our case is the first report on the abundance of ATP synthase and PGK in response to elevated $\mathrm{CO}_{2}$ were found in $\mathrm{C}_{4}$ plant species grown under heat stress. Our previous study in $\mathrm{C}_{3}$ plant species found differential responses of photosynthesis-related proteins to elevated $\mathrm{CO}_{2}$ different from found in bermudagrass in our study. In tall fescue, the abundance of ATP synthase subunit and PGK did not change in response to elevated $\mathrm{CO}_{2}$ under heat stress 

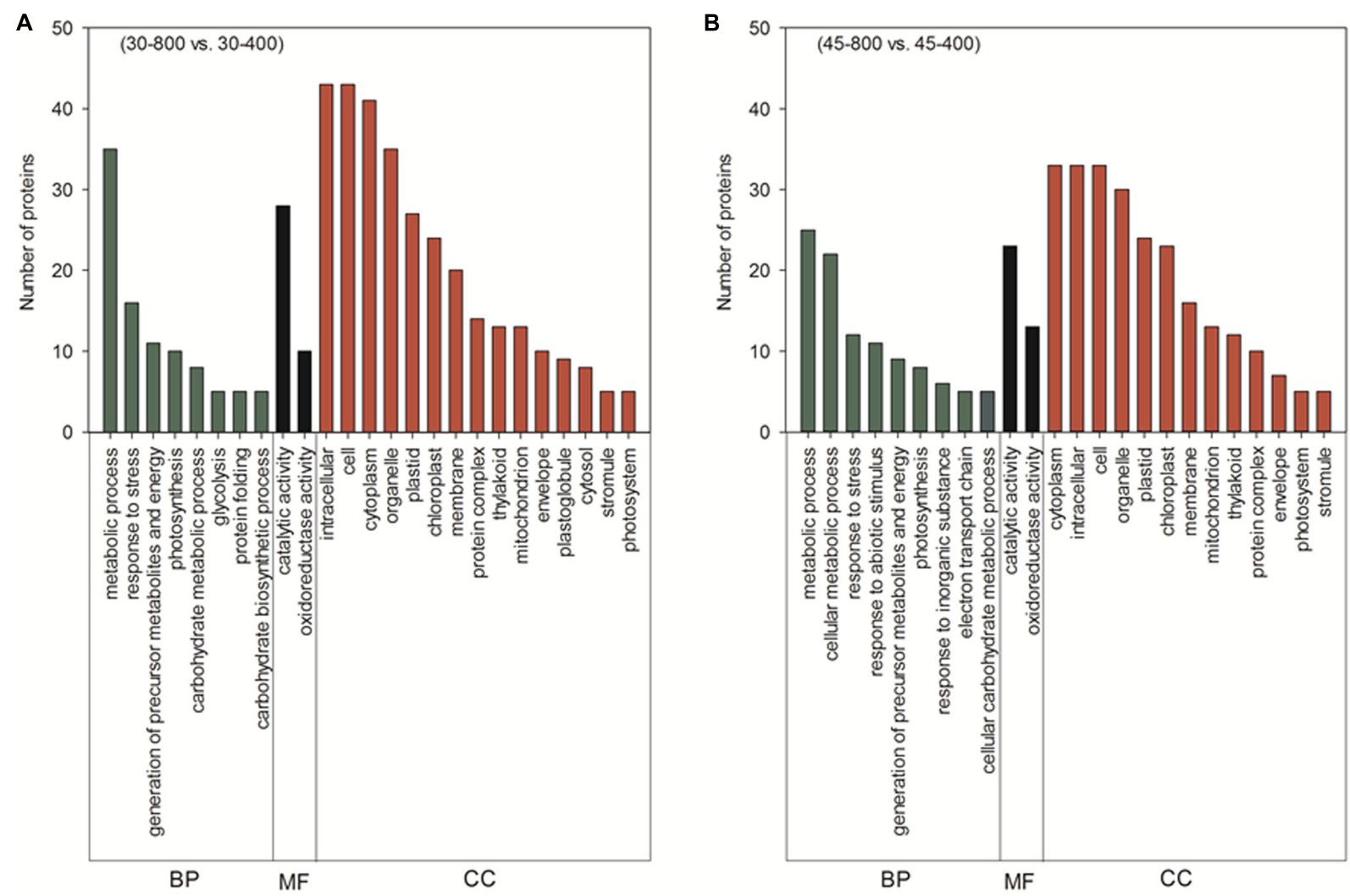

FIGURE 11 | Cluster analysis from gene ontology (GO) analysis of differentially expressed proteins in response to different $\mathrm{CO}_{2}$ concentrations under normal temperature (A) and heat stress (B) in leaves of bermudagrass. The treatments symbols are 30 and 45 for normal temperature control and heat stress and 400 and 800 for ambient $\mathrm{CO}_{2}$ and elevated $\mathrm{CO}_{2}$ concentrations, respectively. BP, biological process; MF, molecular function; CC, cellular component.
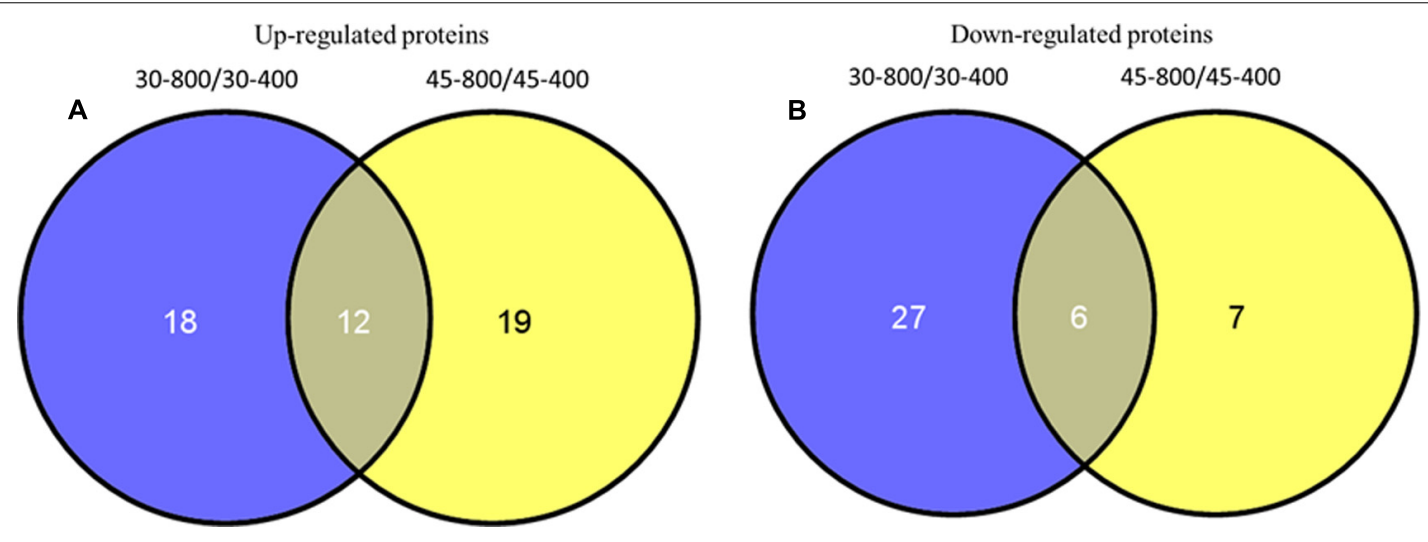

FIGURE 12 | Venn analysis of up-regulated proteins (A) and down-regulated proteins (B) identified in bermudagrass at 28 days of treatments. The treatments

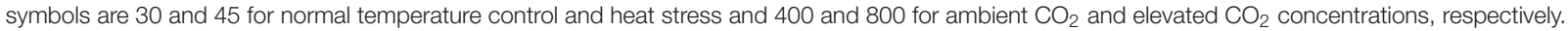

(Yu et al., 2014). The increase in abundance and activity of a single or some enzyme(s) during photosynthesis could enhance carbon assimilation (Rosenthal et al., 2011). Taken together, the enhanced accumulation of proteins involved in photosynthesis by elevated $\mathrm{CO}_{2}$ under heat stress in bermudagrass suggested that elevated $\mathrm{CO}_{2}$ could help to maintain photosynthesis to withstand the adverse environments as various proteins are involved in the light harvesting, electron transport, and carbohydrate assimilation processes of photosynthesis.

Other proteins related to photosynthesis such as GAPDH, OEE, PGR exhibited the enhanced expression in plants grown at elevated $\mathrm{CO}_{2}$ concentration under both temperatures in our study. GAPDH could convert G3P to D-glycerate 1,3bisphosphate as well as mediating the formation of $\mathrm{NADH}$ 

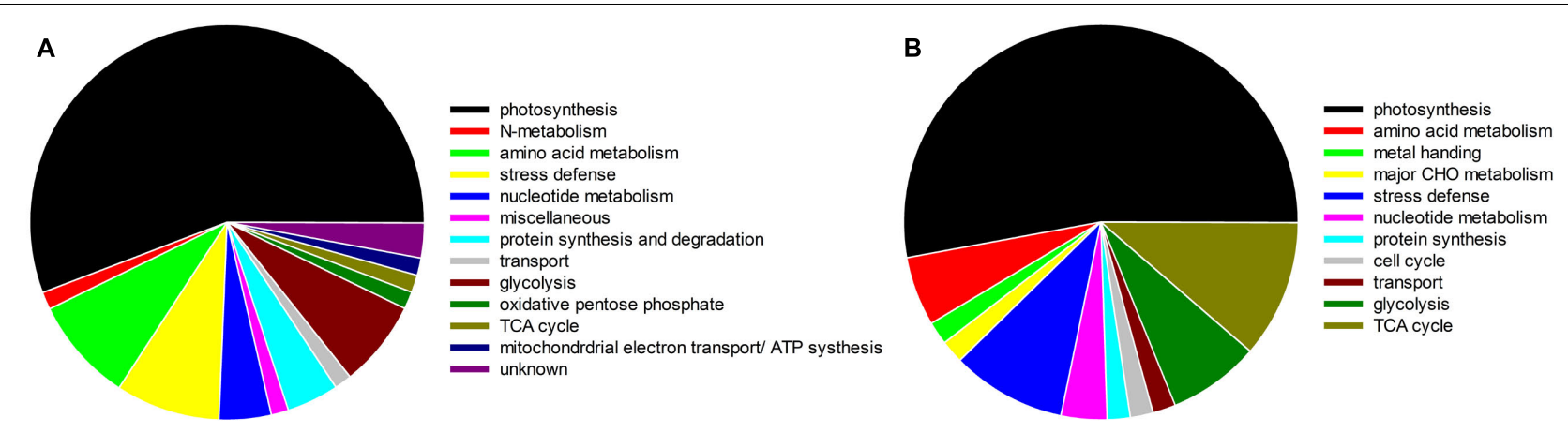

FIGURE 13 | Functional classification of $\mathrm{CO}_{2}$ responsive proteins identified in bermudagrass grown under normal temperature (A) and heat stress (B) at 28 days of treatments.

and ATP (Tristan et al., 2011). It has multiple functions, such as two chloroplastic forms playing photosynthetic function locating in chloroplast and one cytosolic form participating in glycolysis in higher plants (Sparla et al., 2005; Tarze et al., 2007). In chloroplasts, GAPDH catalyzes a reaction of NADPHconsuming which is regulated by light utilizing thioredoxins and metabolites during Calvin cycle (Sparla et al., 2005). Various stresses caused the decline in chloroplastic GAPDH whereas stress-tolerant species exhibited higher GAPDH abundance than stress-sensitive plants, such as creeping bentgrass under heat stress (Xu and Huang, 2010a; Merewitz et al., 2011), salinity stress (Xu and Huang, 2010b) and drought stress (Burgess and Huang, 2016). Plants with lower GAPDH abundance were generally associated with decreased photosynthetic capacity resulted from reduced RuBP regeneration rate, followed with the decline in accumulation of photosynthetic products (Price et al., 1995; Burgess and Huang, 2016). However, elevated $\mathrm{CO}_{2}$ had no effects on chloroplastic GAPDH abundance under heat stressed condition but caused significant decrease under non-stressed control plants ( $Y u$ et al., 2014). Overall, our study suggested that enhanced abundance of photosynthesisrelated proteins could contribute to the improved photosynthetic activities by elevated $\mathrm{CO}_{2}$, particularly under heat stress, which could be reflected with improved $P_{\mathrm{n}}$ and increased content of sugars, such as fructose, glucose, sucrose, erythrose, and glucopyranose.

\section{Proteins and Metabolites in Respiration Regulated by Elevated $\mathrm{CO}_{2}$ under Heat Stress}

It has been widely known that glycolysis and TCA cycle are vital pathways for energy supply, amino acid synthesis and various other biological processes in plants (Fernie et al., 2004; Ma et al., 2016). As substrate of photosynthesis for carboxylation, plants grown at elevated $\mathrm{CO}_{2}$ tended to accumulate the larger amount of non-structural carbohydrates (Yu et al., 2012a; Song et al., 2014). Most monosaccharides (glucose, fructose, galactose, etc.) as substrate or intermediates play vital roles during glycolysis. Glycolysis pathway could convert glucose into pyruvate via a series of intermediate metabolites and cytosolic GAPDH is one of essential enzymes catalyzing the sixth step of respiratory glycolysis to convert G3P to 1, 3-bisphosphateglycerate (1, 3$\mathrm{BPG}$ ) which is one of the most important reactions during the glycolytic pathway (Mijeong et al., 2000). The increase of pyruvic acid (pyruvate) as the product of glycolysis, followed by the enhanced content of valine, isoleucine and alanine, was partly due to elevated $\mathrm{CO}_{2}$-caused accumulation of glucose under heat stress in our study, since those metabolites are all derived from glucose. In $\mathrm{C}_{3}$ tall fescue, we also observed the significant increases in valine and alanine but not for isoleucine resulted from elevated $\mathrm{CO}_{2}$ under heat stress ( $\mathrm{Yu}$ et al., 2012a). During the pathway of glycolysis, the abundance of GAPDH in cytosol (n776, n784, n816 except n808) and phosphoglycerate mutase (PGAM, n382) exhibited the downregulation in response to elevated $\mathrm{CO}_{2}$ rather than ambient $\mathrm{CO}_{2}$ under normal temperature, while under heat stressed conditions elevated $\mathrm{CO}_{2}$ caused up-regulation in GAPDH (h845, h1164, h1167 except h1182) in bermudagrass (Figure 16). GAPDH might serve as a provider of additional energy for plant growth and development under stressed conditions and stress tolerance could be enhanced by improved abundance of GAPDH to cope with environmental stresses (Mijeong et al., 2000; Bertrand et al., 2007). In $\mathrm{C}_{3}$ plants, no consistent changes were found due to variations in plant species. For example, in tall fescue and creeping bentgrass, the abundance of cytosolic GAPDH exhibited either no changes or decrease under elevated $\mathrm{CO}_{2}$ and heat stressed condition ( $\mathrm{Yu}$ et al., 2014; Burgess and Huang, 2016). Kappachery et al. (2015) found that GAPDH genesilenced lines showed more sensitive traits to drought stress than non-silenced lines in potato (Solanum tuberosum). By contrast, the higher shoot length and weight were detected in GAPDH overexpression transgenic plants compared with wild-type plants (Kappachery et al., 2015). In the level of transcription in potato, cytosolic GAPDH RNA accumulation was also increased under biological stress (Laxalt et al., 1996). Therefore, in our study, the higher abundance of GAPDH caused by elevated $\mathrm{CO}_{2}$ was beneficial for energy supply to support plant growth under heat stress.

Malate dehydrogenase $(\mathrm{MDH})$ acts as an enzyme to catalyze the oxidation of malate to oxaloacetate via the reduction of $\mathrm{NAD}^{+}$to $\mathrm{NADH}$ in mitochondrial matrix during TCA cycle 

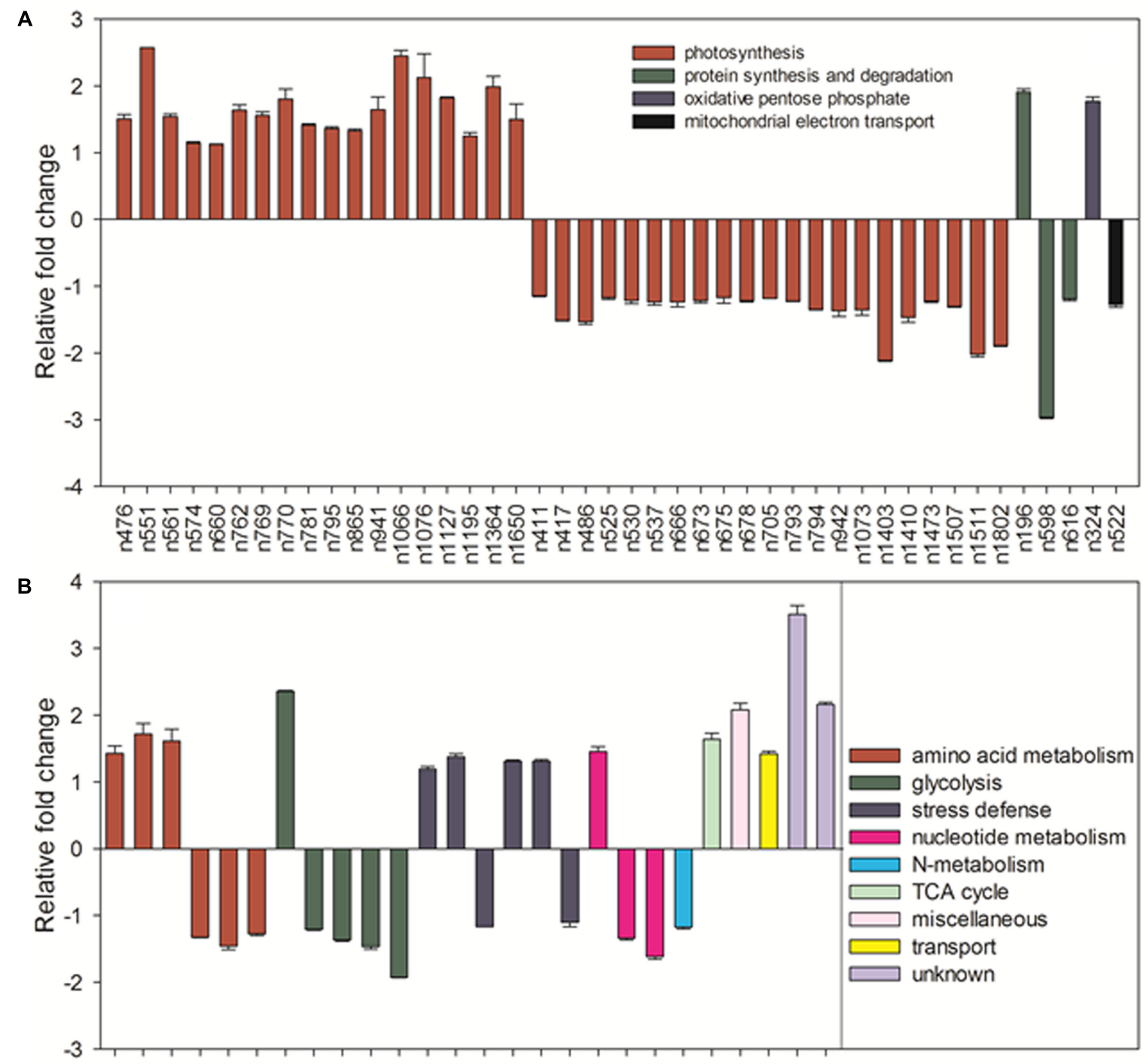

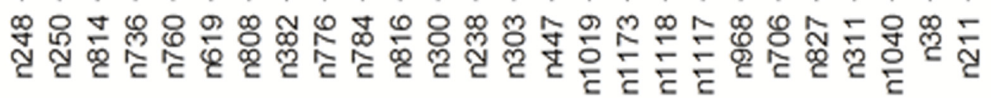

FIGURE 14 | Comparison of protein abundance caused by elevated $\mathrm{CO}_{2}\left(800 \mu \mathrm{mol} \cdot \mathrm{mol}^{-1}\right)$ with ambient $\mathrm{CO}_{2}\left(400 \mu \mathrm{mol}^{-\mathrm{mol}^{-1}}\right)$ under normal temperature control $\left(30^{\circ} \mathrm{C}\right)$. Charts are organized by the functional category of proteins involved in photosynthesis, protein synthesis and degradation, oxidative pentose phosphate and mitochondrial electron transport as shown in (A) as well as amino acid metabolism, glycolysis, stress defense, nucleotide metabolism, N-metabolism, TCA cycle, miscellaneous, transport and unknown proteins as shown in (B). The values of the mean \pm SE represent the relative expression fold change of proteins in response to elevated $\mathrm{CO}_{2}$ under normal temperature. Labels with ' $n$ ' in X-axle were same as Table $\mathbf{2}$.

(Musrati et al., 1998). Environmental stresses including drought (Burgess and Huang, 2016), heat (Xu and Huang, 2010a), salinity (Xu et al., 2010) and Al-stress (Ramírez-Benítez et al., 2008) have been shown to decrease the level of $\mathrm{MDH}$ in various plant species. However, limited studies about $\mathrm{MDH}$ were found in plants grown at elevated $\mathrm{CO}_{2}$ concentrations, especially under stressed conditions (Burgess and Huang, 2016). In this study, elevated $\mathrm{CO}_{2}$-responsive $\mathrm{MDH}$ (n827, h1237, h1242, h1258) involved in TCA cycle exhibited up-regulated expression regardless of temperatures, suggesting that $\mathrm{CO}_{2}$ inhibited the heat-induced reduction in $\mathrm{MDH}$ to catalyze the enhanced malate (malic acid) to oxaloacetate (oxaloacetic acid) during malate metabolism.

\section{Amino Acid Metabolism and GABA Shunt Regulated by Elevated $\mathrm{CO}_{2}$ under Heat Stress}

In addition to function in TCA cycle, $\mathrm{MDH}$ also participates in the process of amino acid synthesis due to the relations among malate, oxaloacetate and aspartate (Musrati et al., 1998; Wen et al., 2015). Several amino acids including aspartate 


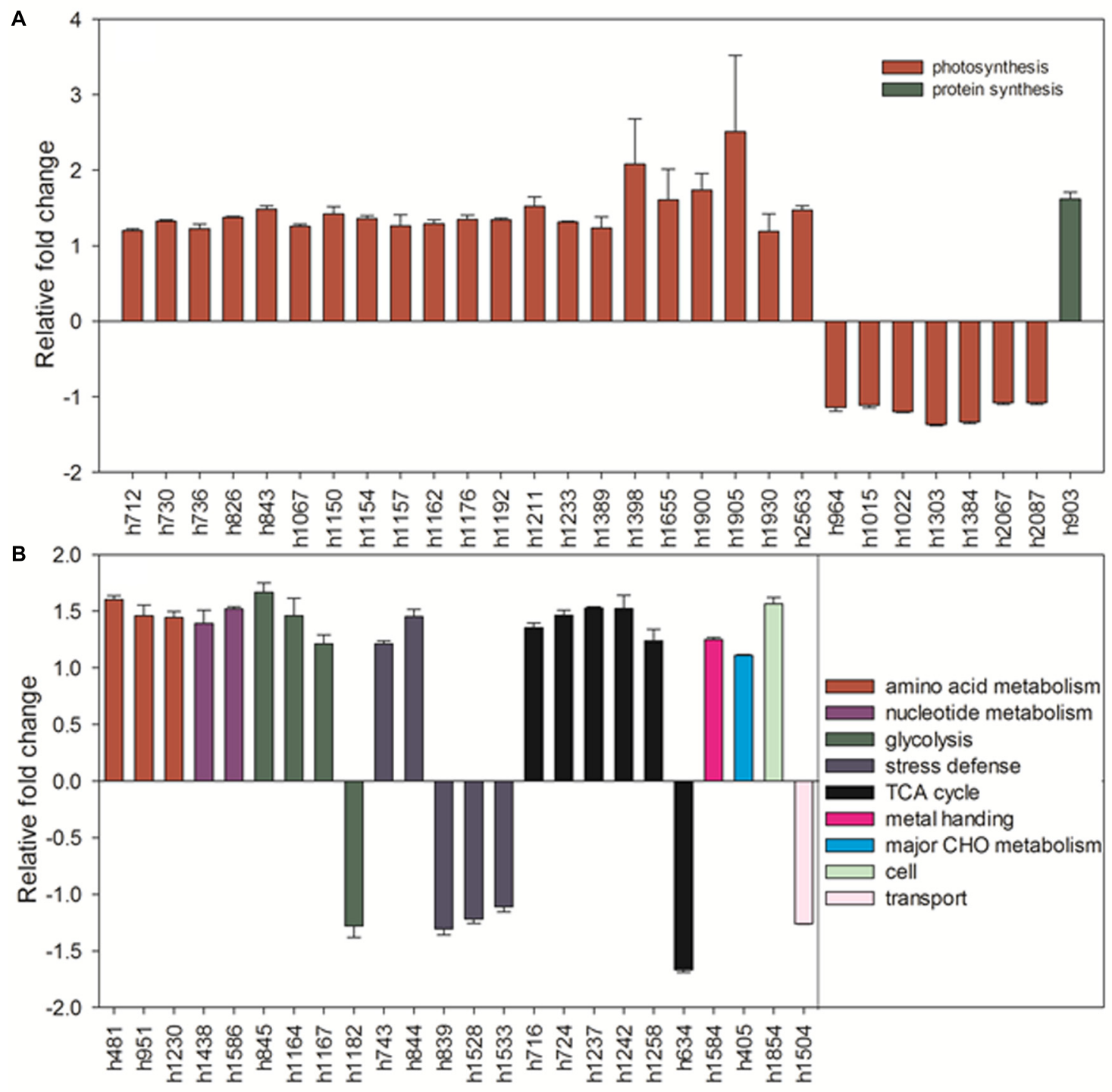

FIGURE 15 | Comparison of protein abundance caused by elevated $\mathrm{CO}_{2}\left(800 \mu \mathrm{mol} \cdot \mathrm{mol}^{-1}\right)$ with ambient $\mathrm{CO}_{2}\left(400 \mu \mathrm{mol} \cdot \mathrm{mol}^{-1}\right)$ under heat stress $\left(45^{\circ} \mathrm{C}\right)$. Charts are organized by the functional category of proteins involved in photosynthesis and protein synthesis as shown in (A) as well as amino acid metabolism, glycolysis, stress defense, TCA cycle, metal handing, major $\mathrm{CHO}$ metabolism, cell and transport as shown in (B). The values of the mean $\pm \mathrm{SE}$ represent the relative expression fold change of proteins in response to elevated $\mathrm{CO}_{2}$ under heat stress. Labels with ' $h$ ' in X-axle were same as Table 2.

(aspartic acid), methionine, threonine, isoleucine, lysine derived from oxaloacetate and aspartate is the precursor of methionine, threonine, isoleucine and lysine (Muehlbauer et al., 1994). Along with the significant increase in malic acid and aspartic acid, the content of threonine, isoleucine and lysine were stimulated by elevated $\mathrm{CO}_{2}$ during heat stress. Furthermore, the content of alanine, valine and serine were also enhanced by elevated $\mathrm{CO}_{2}$ compared with ambient $\mathrm{CO}_{2}$ under heat stress. Alanine, valine and serine are used for synthesis of several proteins and associated with many metabolic processes (Bourguignon et al., 1999). The stimulation of elevated $\mathrm{CO}_{2}$ concentration on the content of alanine, valine and serine was found in other species under abiotic stresses, as previously reported in $\mathrm{C}_{3}$ grass species under heat stress ( $\mathrm{Yu}$ et al., 2012a) and tree seedlings under drought stress (Tschaplinski et al., 1995). The increase in synthesis of both alanine and valine in present study is directly associated with the higher content of pyruvate (pyruvate acid) which is the final product of glycolysis (Schulzesiebert et al., 1984). Superior stress tolerance has been reported with the higher content of alanine, valine and serine as well as other amino acids such as GABA, glutamic acid, proline and 5-oxoproline involved in the GABA shunt pathway in plant species, including perennial grasses (Merewitz et al., 2012; Xu et al., 2013; Shi et al., 2014; Li et al., 2016a,b). The GABA shunt was considered to be a part of the TCA cycle during respiration besides 


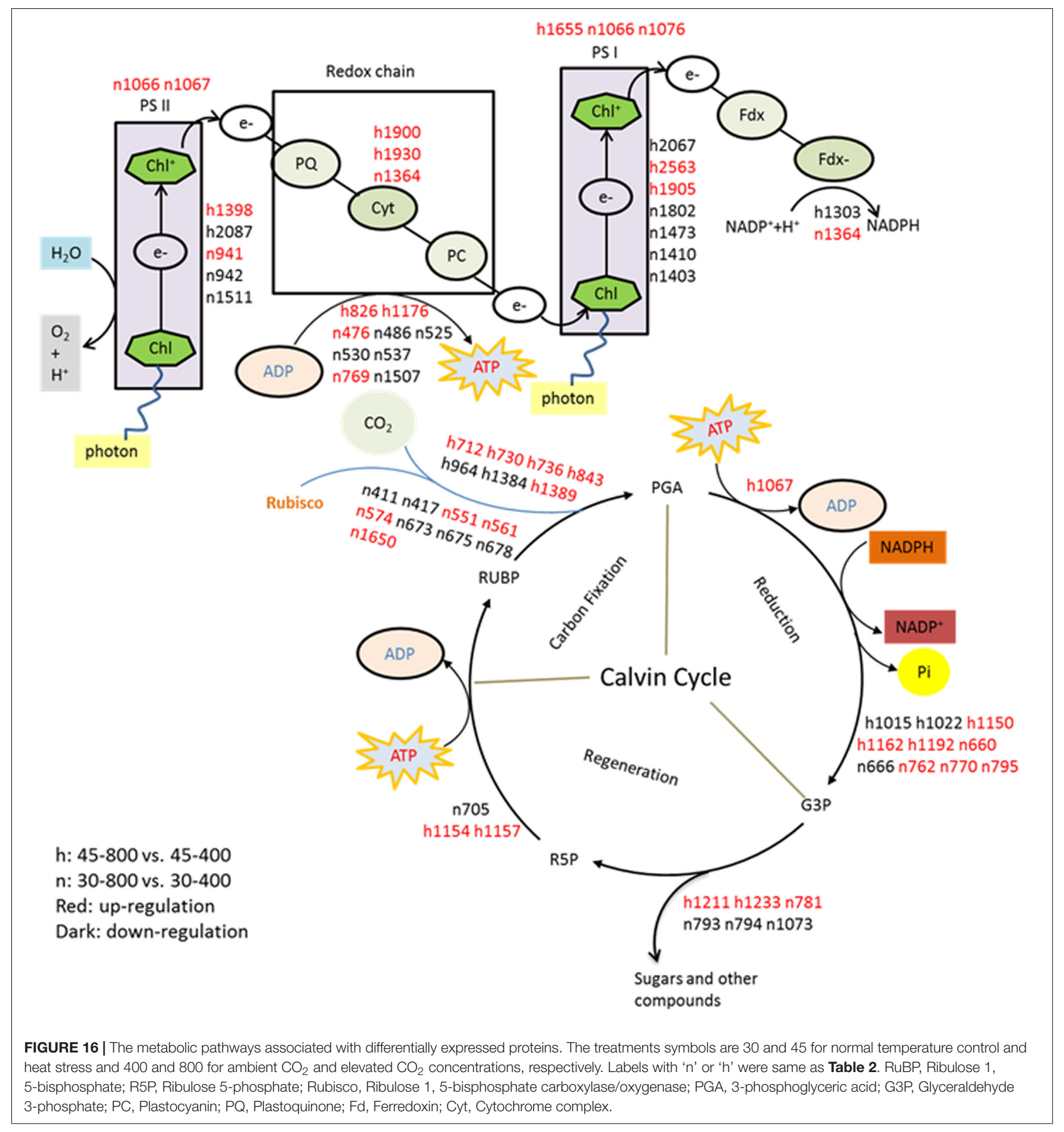

its central role in primary carbon and nitrogen metabolism (Fait et al., 2008). In tall fescue, the content of GABA was significantly decreased by elevated $\mathrm{CO}_{2}$ under high temperature (Yu et al., 2014). While, in bermudagrass of this case, GABA and glutamic acid exhibited the opposite response to elevated $\mathrm{CO}_{2}$ under heat stress. Increased GABA caused the enhanced content of alanine and pyruvate which was turned into TCA cycle and proline metabolism. The content of all amino acids except arginine during GABA shunt was increased by elevated $\mathrm{CO}_{2}$ under heat stress suggesting a predominant role of elevated $\mathrm{CO}_{2}$ in carbon and nitrogen metabolism in $\mathrm{C}_{4}$ bermudagrass.

Proteins including methionine synthase (MS), cysteine synthase (CSase) and S-adenosylmethionine synthase (SAMS) associated with amino acid metabolism were up-regulated by 1.4to 1.6 -fold by elevated $\mathrm{CO}_{2}$ under heat stress. MS and SAMS serve 
as regulators in the synthesis and degradative pathways of various amino acids (Bohnert and Jensen, 1996). It was detected by the same proteomic analysis that many proteins involved in amino acid metabolism accumulated more or degraded less in stresstolerant plants, such as MS and SAMS (Merewitz et al., 2011). CSase functions in the final strep in cysteine synthesis in plants. Plants with overexpressing CSase gene displayed high tolerance to toxic environmental pollutants, such as sulfur dioxide and sulfite (Noji et al., 2001), cadmium toxicity (Harada et al., 2001) in tobacco and aluminum toxicity in rice (Yang et al., 2007). The accumulation of many amino acids as well as proteins involved in amino acid metabolism in this study could contribute to elevated $\mathrm{CO}_{2}$-improved heat tolerance.

In summary, elevated $\mathrm{CO}_{2}$ concentration suppressed heatinduced damages in bermudagrass, as shown by the increased $P_{\mathrm{n}}$, Chl and $F_{\mathrm{v}} / F_{\mathrm{m}}$. The improvement of heat tolerance under elevated $\mathrm{CO}_{2}$ could be associated with some important metabolic pathways during which proteins and metabolites were up-regulated, including proteins, sugars and/or amino acids involved in light reaction (ATP synthase subunit and photosystem I reaction center subunit) and carbon fixation of photosynthesis (GAPDH, FBA, PGK, SBPase and sugars),

\section{REFERENCES}

Abbasi, F. M., and Komatsu, S. (2004). A proteomic approach to analyze saltresponsive proteins in rice leaf sheath. Proteomics 4, 2072-2081. doi: 10.1002/ pmic. 200300741

Abebe, A., Pathak, H., Singh, S. D., Bhatia, A., Harit, R. C., and Kumar, V. (2016). Growth, yield and quality of maize with elevated atmospheric carbon dioxide and temperature in north-west India. Agric. Ecosyst. Environ. 218, 66-72. doi: 10.1016/j.agee.2015.11.014

Alonso, A., Pérez, P. A., and Martinez-Carrasco, R. (2009). Growth in elevated $\mathrm{CO}_{2}$ enhances temperature response of photosynthesis in wheat. Physiol. Plant. 135, 109-120. doi: 10.1111/j.1399-3054.2008.01177.x

Arnon, D. I. (1949). Copper enzymes in isolated chloroplasts. Polyphenoloxidase in Beta vulgaris. Plant Physiol. 24, 1-15. doi: 10.1104/pp.24.1.1

Bencze, S., Veisz, O., and Bedo, Z. (2005). Effect of elevated $\mathrm{CO}_{2}$ and high temperature on the photosynthesis and yield of wheat. Cereal Res. Commun. 33, 385-388. doi: 10.1556/CRC.33.2005.1.95

Bernstein, B. E., Michels, P. A., and Hol, W. G. (1997). Synergistic effects of substrate-induced conformational changes in phosphoglycerate kinase activation. Nature 385, 275-278. doi: 10.1038/385275a0

Bertrand, A., Prévost, D., Bigras, F. J., and Castonguay, Y. (2007). Elevated atmospheric $\mathrm{CO}_{2}$ and strain of rhizobium alter freezing tolerance and coldinduced molecular changes in alfalfa (Medicago sativa). Ann. Bot. 99, 275-284. doi: $10.1093 / \mathrm{aob} / \mathrm{mcl} 254$

Bevan, M., Bancroft, I., Bent, E., Love, K., Goodman, H., Dean, C., et al. (1998). Analysis of $1.9 \mathrm{Mb}$ of contiguous sequence from chromosome 4 of Arabidopsis thaliana. Nature 391, 485-488. doi: 10.1038/ 35140

Bohnert, H. J., and Jensen, R. G. (1996). Strategies for engineering water-stress tolerance in plants. Trends Biotechnol. 14, 89-97. doi: 10.1016/0167-7799(96) 80929-2

Bourguignon, J., Rebeille, F., and Douce, R. (1999). "Serine and glycine metabolism in higher plants," in Plant Amino Acids, ed. B. K. Singh (New York, NY: Marcel Dekker), 111-146.

Bradford, M. M. (1976). A rapid and sensitive method for the quantitation of microgram quantities of protein utilizing the principle of protein-dye binding. Anal. Biochem. 72, 248-254. doi: 10.1016/0003-2697(76)90527-3

Burgess, P., and Huang, B. (2014). Root protein metabolism in association with improved root growth and drought tolerance by elevated carbon dioxide in creeping bentgrass. Field Crops Res. 165, 80-91. doi: 10.1016/j.fcr.2014.05.003 glycolysis (GAPDH, glucose, fructose and galactose) and TCA cycle (pyruvic acid, malic acid and $\mathrm{MDH}$ ) of respiration, amino acid metabolism (aspartic acid, methionine, threonine, isoleucine, lysine, valine, alanine and isoleucine) as well as the GABA shunt (GABA, glutamic acid, alanine, proline and 5oxoproline). The molecular factors and mechanisms underlying the metabolic changes caused by elevated $\mathrm{CO}_{2}$ during plant responses to heat stress require further investigation.

\section{AUTHOR CONTRIBUTIONS}

JY and $\mathrm{BH}$ designed the experiments and wrote the manuscript. JY and RL conducted the experiments. NF helped with the sample analysis. ZY arranged the experiments and did the data analysis.

\section{ACKNOWLEDGMENTS}

This research was supported by the National Natural Science Foundation of China (31301799) and the Fundamental Research Funds for the Central Universities (KYZ201673).

Burgess, P., and Huang, B. (2016). Leaf protein abundance associated with improved drought tolerance by elevated carbon dioxide in creeping bentgrass. J. Am. Soc. Hortic. Sci. 141, 85-96.

Fait, A., Fromm, H., Walter, D., Galili, G., and Fernie, A. R. (2008). Highway or byway: the metabolic role of the GABA shunt in plants. Trends Plant Sci. 13, 14-19. doi: 10.1016/j.tplants.2007.10.005

Fernie, A. R., Carrari, F., and Sweetlove, L. J. (2004). Respiratory metabolism: glycolysis, the TCA cycle and mitochondrial electron transport. Curr. Opin. Plant Biol. 7, 254-261. doi: 10.1016/j.pbi.2004.03.007

Figueiredo, N., Carranca, C., Trindade, H., Pereira, J., Goufo, P., Coutinho, J., et al. (2015). Elevated carbon dioxide and temperature effects on rice yield, leaf greenness, and phenological stages duration. Paddy Water Environ. 13, 313-324. doi: 10.1007/s10333-014-0447-x

Fukayama, H., Fukuda, T., Masumoto, C., Taniguchi, Y., Sakai, H., Cheng, W., et al. (2009). Rice plant response to long term $\mathrm{CO}_{2}$ enrichment: gene expression profiling. Plant Sci. 177, 203-210. doi: 10.1016/j.plantsci.2009.05.014

Hamerlynck, E. P., Huxman, T. E., Loik, M. E., and Smith, S. D. (2000). Effects of extreme high temperature, drought and elevated $\mathrm{CO}_{2}$ on photosynthesis of the Mojave Desert evergreen shrub, Larrea tridentata. Plant Ecol. 148, 183-193. doi: 10.1023/A:1009896111405

Harada, E., Choi, Y. E., Tsuchisaka, A., Obata, H., and Sano, H. (2001). Transgenic tobacco plants expressing a rice cysteine synthase gene are tolerant to toxic levels of cadmium. J. Plant Physiol. 158, 655-661. doi: 10.1078/0176-161700314

Hoagland, D. R., and Arnon, D. I. (1950). The water-culture method for growing plans without soil. Calif. Agric. Exp. Stn. Circ. 347, 1-32.

Högy, P., Zörb, C., Langenkämper, G., Betsche, T., and Fangmeier, A. (2009). Atmospheric $\mathrm{CO}_{2}$ enrichment changes the wheat grain proteome. J. Cereal Sci. 50, 248-254. doi: 10.1016/j.jcs.2009.06.002

Huang, B., and $\mathrm{Xu}, \mathrm{Y}$. (2015). Cellular and molecular mechanisms for elevated $\mathrm{CO}_{2}$-regulation of plant growth and stress adaptation. Crop Sci. 55, 1405. doi: $10.2135 /$ cropsci2014.07.0508

Intergovernmental Panel on Climate Change [IPCC] (2007). Climate Change: Fourth Assessment Report. London: Cambridge University Press.

Kappachery, S., Baniekal-Hiremath, G., Yu, J. W., and Park, S. W. (2015). Effect of over-and under-expression of glyceraldehyde 3-phosphate dehydrogenase on tolerance of plants to water-deficit stress. Plant Cell Tissue Organ Cult. 121, 97-107. doi: 10.1007/s11240-014-0684-0

Kirkham, M. B. (2011). Elevated Carbon Dioxide: Impacts on Soil and Plant Water Relations. Boca Raton, FL: CRC Press. doi: 10.1201/b10812 
Lai, S. K., Zhuang, S. T., Wu, Y. Z., Wang, Y. X., Zhu, J. G., Yang, L. X., et al. (2015). Impact of elevated atmospheric $\mathrm{CO}_{2}$ concentration and temperature on growth and development of super rice. Am. J. Roentgenol. 34, 1253-1262.

Laxalt, A. M., Cassia, R. O., Sanllorenti, P. M., Madrid, E. A., Andreu, A. B., Daleo, G. R., et al. (1996). Accumulation of cytosolic glyceraldehyde-3-phosphate dehydrogenase RNA under biological stress conditions and elicitor treatments in potato. Plant Mol. Biol. 30, 961-972. doi: 10.1007/BF00020807

Lefebvre, S., Lawson, T., Zakhleniuk, O. V., Lloyd, J. C., Raines, C. A., and Fryer, M. (2005). Increased sedoheptulose-1,7-bisphosphatase activity in transgenic tobacco plants stimulates photosynthesis and growth from an early stage in development. Plant Physiol. 138, 451-460. doi: 10.1104/pp.104.055046

Li, Z., Yu, J., Peng, Y., and Huang, B. (2016a). Metabolic pathways regulated by $\gamma$-aminobutyric acid (GABA) contributing to heat tolerance in creeping bentgrass (Agrostis stolonifera). Sci. Rep. 6:30338. doi: 10.1038/srep 30338

Li, Z., Yu, J., Peng, Y., and Huang, B. (2016b). Metabolic pathways regulated by abscisic acid, salicylic acid, and $\gamma$-aminobutyric acid in association with improved drought tolerance in creeping bentgrass (Agrostis stolonifera). Physiol. Plant. 159, 42-58. doi: 10.1111/ppl.12483

Ma, X., Xu, Q., Meyer, W. A., and Huang, B. (2016). Hormone regulation of rhizome development in tall fescue (Festuca arundinacea) associated with proteomic changes controlling respiratory and amino acid metabolism. Ann. Bot. 118, 481-494. doi: 10.1093/aob/mcw120

Merewitz, E. B., Du, H., Yu, W., Liu, Y., Gianfagna, T., and Huang, B. (2012). Elevated cytokinin content in ipt transgenic creeping bentgrass promotes drought tolerance through regulating metabolite accumulation. J. Exp. Bot. 63, 1315-1328. doi: 10.1093/jxb/err372

Merewitz, E. B., Gianfagna, T., and Huang, B. (2011). Protein accumulation in leaves and roots associated with improved drought tolerance in creeping bentgrass expressing an ipt gene for cytokinin synthesis. J. Exp. Bot. 62, 5311-5333. doi: 10.1093/jxb/err166

Mijeong, J., Soochul, P., Hawkbin, K., and Myungok, B. (2000). Isolation and characterization of the gene encoding glyceraldehyde-3-phosphate dehydrogenase. Biochem. Biophys. Res. Commun. 278, 192-196. doi: 10.1006/ bbrc. 2000.3732

Morgan, J. A., Lecain, D. R., Pendall, E., Blumenthal, D. M., Kimball, B. A., Carrillo, Y., et al. (2011). C4 grasses prosper as carbon dioxide eliminates desiccation in warmed semi-arid grassland. Nature 476, 202-205. doi: 10.1038/ nature 10274

Muehlbauer, G. J., Gengenbach, B. G., and Somers, D. A. (1994). Genetic and amino-acid analysis of two maize threonine-overproducing, lysine-insensitive aspartate kinase mutants. Theor. Appl. Gen. 89, 767-774. doi: 10.1007/ BF00223717

Musrati, R. A., Kollárová, M., Mernik, N., and Mikulásová, D. (1998). Malate dehydrogenase: distribution, function and properties. Gen. Physiol. Biophys. 17, 193-210.

Noji, M., Aono, M., and Saito, K. (2001). Cysteine synthase overexpression in tobacco confers tolerance to sulfur-containing environmental pollutants. Plant Physiol. 126, 973. doi: 10.1104/pp.126.3.973

Prasad, P. V. V., Boote, K. J., and Allen, L. H. Jr. (2006). Adverse high temperature effects on pollen viability, seed-set, seed yield and harvest index of grainsorghum [Sorghum bicolor (L.) Moench] are more severe at elevated carbon dioxide due to higher tissue temperatures. Agric. For. Meteorol. 139, 237-251. doi: 10.1016/j.agrformet.2006.07.003

Prasad, P. V. V., Boote, K. J., Allen, L. H. Jr., and Thomas, J. M. G. (2002). Effects of elevated temperature and carbon dioxide on seed-set and yield of kidney bean (Phaseolus vulgaris L.). Glob. Change Biol. 8, 710-721. doi: 10.1046/j.1365-2486. 2002.00508.x

Prasad, P. V. V., Boote, K. J., Allen, L. H., and Thomas, J. M. G. (2010). Super-optimal temperatures are detrimental to peanut (Arachis hypogaea L.) reproductive processes and yield at both ambient and elevated carbon dioxide. Glob. Change Biol. 9, 1775-1787. doi: 10.1046/j.1365-2486.2003.00708.x

Prasad, P. V. V., Boote, K. J., Jcv, V., and Lhjr, A. (2004). The carbohydrate metabolism enzymes sucrose-P synthase and ADG-pyrophosphorylase in phaseolus bean leaves are up-regulated at elevated growth carbon dioxide and temperature. Plant Sci. 166, 1565-1573. doi: 10.1016/j.plantsci.2004.02.009

Price, G. D., Evans, J. R., Von, C. S., Yu, J. W., and Badger, M. R. (1995). Specific reduction of chloroplast glyceraldehyde-3-phosphate dehydrogenase activity by antisense RNA reduces $\mathrm{CO}_{2}$ assimilation via a reduction in ribulose bisphosphate regeneration in transgenic tobacco plants. Planta 195, 369-378. doi: 10.1007/BF00202594

Pritchard, S. H. G., Rogers, H. O. H., Prior, S. A., and Peterson, C. T. M. (1999). Elevated $\mathrm{CO}_{2}$ and plant structure: a review. Glob. Change Biol. 5, 807-837. doi: 10.1046/j.1365-2486.1999.00268.x

Qaderi, M. M., Kurepin, L. V., and Reid, D. M. (2006). Growth and physiological responses of canola (Brassica napus) to three components of global climate change: temperature, carbon dioxide and drought. Physiol. Plant. 128, 710-721. doi: 10.1111/j.1399-3054.2006.00804.x

Qiu, Y., Su, M., Liu, Y., Chen, M., Gu, J., Zhang, J., et al. (2007). Application of ethyl chloroformate derivatization for gas chromatography-mass spectrometry based metabonomic profiling. Anal. Chim. Acta 583, 277-283. doi: 10.1016/j. aca.2006.10.025

Raines, C. A., Lloyd, J. C., and Dyer, T. A. (1999). New insights into the structure and function of sedoheptulose-1,7-bisphosphatase; an important but neglected Calvin cycle enzyme. J. Exp. Bot. 50, 1-8.

Ramírez-Benítez, J. E., Chee-González, L., and Hernandez-Sotomayor, S. M. T. (2008). Aluminium induces changes in organic acids metabolism in Coffea arabica suspension cells with differential Al-tolerance. J. Inorg. Biochem. 102, 1631-1637. doi: 10.1016/j.jinorgbio.2008.03.002

Read, J. J., and Morgan, J. A. (1996). Growth and partitioning in Pascopyrum smithii (C3) and Bouteloua gracilis (C4) as influenced by carbon dioxide and temperature. Ann. Bot. 77, 487-496. doi: 10.1006/anbo.1996.0059

Rizhsky, L., Liang, H., Shuman, J., Shulaev, V., Davletova, S., and Mittler, R. (2004). When defense pathways collide. The response of Arabidopsis to a combination of drought and heat stress. Plant Physiol. 134, 1683-1696. doi: 10.1104/pp.103. 033431

Roessner, U., Wagner, C., Kopka, J., Trethewey, R. N., and Willmitzer, L. (2000). Simultaneous analysis of metabolites in potato tuber by gas chromatographymass spectrometry. Plant J. 23, 131-142. doi: 10.1046/j.1365-313x.2000. 00774.x

Rosenthal, D. M., Locke, A. M., Khozaei, M., Raines, C. A., Long, S. P., and Ort, D. R. (2011). Over-expressing the $C_{3}$ photosynthesis cycle enzyme Sedoheptulose-1-7 Bisphosphatase improves photosynthetic carbon gain and yield under fully open air $\mathrm{CO}_{2}$ fumigation (FACE). BMC Plant Biol. 11:123. doi: 10.1186/1471-2229-11-123

Schulzesiebert, D., Heineke, D., Scharf, H., and Schultz, G. (1984). Pyruvatederived amino acids in spinach chloroplasts 1. Plant Physiol. 76, 465-471. doi: 10.1104/pp.76.2.465

Shi, H., Jiang, C., Ye, T., Tan, D. X., Reiter, R. J., Zhang, H., et al. (2014). Comparative physiological, metabolomic, and transcriptomic analyses reveal mechanisms of improved abiotic stress resistance in bermudagrass [Cynodon dactylon (L). Pers.] by exogenous melatonin. J. Integr. Plant Biol. 66, 681-694. doi: $10.1093 /$ jxb/eru373

Song, Y. L., Yu, J. J., and Huang, B. (2014). Elevated $\mathrm{CO}_{2}$-mitigation of high temperature stress associated with maintenance of positive carbon balance and carbohydrate accumulation in Kentucky bluegrass. PLOS ONE 9:e89725. doi: 10.1371/journal.pone.0089725

Sparla, F., Zaffagnini, M., Wedel, N., Scheibe, R., Pupillo, P., and Trost, P. (2005). Regulation of photosynthetic GAPDH dissected by mutants. Plant Physiol. 138, 2210-2219. doi: 10.1104/pp.105.062117

Sujatha, K. B., Uprety, D. C., Rao, D. N., Rao, P. R., and Dwivedi, N. (2008). Up-regulation of photosynthesis and sucrose-P synthase in rice under elevated carbon dioxide and temperature conditions. Plant Soil Environ. 54, $155-162$.

Taiz, L., and Zeiger, E. (2010). Plant Physiology, 5th Edn. Sunderland, MA: Sinauer Associates.

Tanz, S. K., Castleden, I., Hooper, C. M., Vacher, M., Small, I., and Millar, H. A. (2013). SUBA3: a database for integrating experimentation and prediction to define the SUBcellular location of proteins in Arabidopsis. Nucleic Acids Res. 41, 1185-1191. doi: 10.1093/nar/gks1151

Tarze, A., Deniaud, A., Bras, M. L., Maillier, E., Molle, D., Larochette, N., et al. (2007). GAPDH, a novel regulator of the pro-apoptotic mitochondrial membrane permeabilization. Oncogene 26, 2606-2620. doi: 10.1038/sj.onc. 1210074

Thimm, O., Bläsing, O., Gibon, Y., Nagel, A., Meyer, S., Krüger, P., et al. (2004). Mapman: a user-driven tool to display genomics data sets onto diagrams 
of metabolic pathways and other biological processes. Plant J. 37, 914-939. doi: 10.1111/j.1365-313X.2004.02016.x

Tristan, C., Shahani, N., Sedlak, T. W., and Sawa, A. (2011). The diverse functions of GAPDH: views from different subcellular compartments. Cell. Signal. 23, 317-323. doi: 10.1016/j.cellsig.2010.08.003

Tschaplinski, T. J., Stewart, D. B., and Norby, R. J. (1995). Interactions between drought and elevated $\mathrm{CO}_{2}$ on osmotic adjustment and solute concentrations of tree seedlings. New Phytol. 131, 169-177. doi: 10.1111/j.1469-8137.1995. tb05718.x

Wen, W., Li, K., Alseekh, S., Omranian, N., Zhao, L., Zhou, Y., et al. (2015). Genetic determinants of the network of primary metabolism and their relationships to plant performance in a maize recombinant inbred line population. Plant Cell 27, 1839-1856. doi: 10.1105/tpc.15.00208

$\mathrm{Xu}, \mathrm{C}$., and Huang, B. (2008). Root proteomic responses to heat stress in two Agrostis grass species contrasting in heat tolerance. J. Exp. Bot. 59, 4183-4194. doi: $10.1093 /$ jxb/ern258

$\mathrm{Xu}$, C., and Huang, B. (2010a). Differential proteomic response to heat stress in thermal Agrostis scabra and heat-sensitive Agrostis stolonifera. Physiol. Plant. 139, 192-204. doi: 10.1111/j.1399-3054.2010. 01357.x

$\mathrm{Xu}$, C., and Huang, B. (2010b). Comparative analysis of drought responsive proteins in Kentucky bluegrass cultivars contrasting in drought tolerance. Crop Sci. 50, 2543-2552. doi: 10.2135/cropsci2010.03. 0152

Xu, C., Sibicky, T., and Huang, B. (2010). Protein profile analysis of salt-responsive proteins in leaves and roots in two cultivars of creeping bentgrass differing in salinity tolerance. Plant Cell Rep. 29, 595-615. doi: 10.1007/s00299-010-0847-3

$\mathrm{Xu}, \mathrm{Y} ., \mathrm{Du}, \mathrm{H}$. , and Huang, B. (2013). Identification of metabolites associated with superior heat tolerance in thermal bentgrass through metabolic profiling. Crop Sci. 53, 1626-1635. doi: 10.2135/cropsci2013.01.0045
Yang, Q., Wang, Y., Zhang, J., Shi, W., Qian, C., and Peng, X. (2007). Identification of aluminum-responsive proteins in rice roots by a proteomic approach: cysteine synthase as a key player in Al response. Proteomics 7, 737-749. doi: 10.1002/pmic.200600703

Yu, J., Sun, L., Fan, N., Yang, Z., and Huang, B. (2015). Physiological factors involved in positive effects of elevated carbon dioxide concentration on bermudagrass tolerance to salinity stress. Environ. Exp. Bot. 115, 20-27. doi: 10.1016/j.envexpbot.2015.02.003

Yu, J. J., Du, H. M., Xu, M., and Huang, B. R. (2012a). Metabolic responses to heat stress under elevated atmospheric $\mathrm{CO}_{2}$ concentration in a cool-season grass species. J. Am. Soc. Hortic. Sci. 137, 221-228.

Yu, J. J., Chen, L. H., Xu, M., and Huang, B. R. (2012b). Effects of elevated $\mathrm{CO}_{2}$ on physiological responses of tall fescue to elevated temperature, drought stress, and the combined stresses. Crop Sci. 52, 1848-1858. doi: 10.2135/cropsci2012. 01.0030

Yu, J. J., Yang, Z. M., Jespersen, D., and Huang, B. R. (2014). Photosynthesis and protein metabolism associated with elevated $\mathrm{CO}_{2}$-mitigation of heat stress damages in tall fescue. Environ. Exp. Bot. 99, 75-85. doi: 10.1016/j.envexpbot. 2013.09.007

Conflict of Interest Statement: The authors declare that the research was conducted in the absence of any commercial or financial relationships that could be construed as a potential conflict of interest.

Copyright (c) 2017 Yu, Li, Fan, Yang and Huang. This is an open-access article distributed under the terms of the Creative Commons Attribution License (CC BY). The use, distribution or reproduction in other forums is permitted, provided the original author(s) or licensor are credited and that the original publication in this journal is cited, in accordance with accepted academic practice. No use, distribution or reproduction is permitted which does not comply with these terms. 